\title{
An Alternating-Offers Model of Multilateral Negotiations*
}

\author{
Charles J. Thomas \\ Economic Science Institute \& Argyros School of Business and Economics \\ Chapman University
}

October 16, 2012

\begin{abstract}
I develop an infinite-horizon alternating-offers model of multilateral negotiations, a common means of exchange whose strategic complexity has hindered previous modeling efforts. Multilateral negotiations occur in numerous settings in which one party wishes to trade with one of several others, but for concreteness I consider a buyer facing multiple sellers offering potentially different amounts of surplus to be split. The basic model provides surprising insights about introducing competition to an initially bilateral setting, while straightforward extensions provide empirical predictions about how the buyer's choice of conducting procurement via multilateral negotiations or auctions is affected by factors including the number of sellers, uncertainty when making the choice, and costs of participating in the procurement process. More generally the model provides a tractable foundation for analyzing strategic problems in settings featuring multilateral negotiations.
\end{abstract}

\section{Introduction}

Bilateral negotiations play an important role in economic theory and practice, but negotiations often are multilateral in nature. For example, in a procurement setting a firm or government might negotiate to purchase from one of several suppliers whose products differ on dimensions such as quality or goodness-offit. Likewise, a takeover contest might involve multiple potential acquirers who differ in their synergies or opportunity costs from completing the transaction. A high-end job candidate might have several employers maneuvering for position, while a firm contemplating significant foreign direct investment might have multiple governments as eager suitors.

Multilateral negotiations have received relatively little academic attention despite their empirical relevance, perhaps because their strategic complexity has made them difficult to analyze with formal models. They feature elements of bilateral negotiations and auctions, both of which are potentially complex exchange mechanisms that have been the subject of significant amounts of academic research. ${ }^{1}$ However, analyses of bilateral negotiations by definition tend to emphasize bilateral settings, with some exceptions described

${ }^{*}$ Email: charles.j.thomas.phd@gmail.com. Patrick Warren provided helpful comments, as did participants in the Industrial Organization workshop and Junior Faculty Brownbag at Clemson University, and the IFREE lecture series at the Economic Science Institute (ESI) at Chapman University.

JEL: C78, D44, D82

Keywords: negotiations, bargaining, auctions, procurement, dynamic games

${ }^{1}$ For surveys of the bargaining literature see Kennan and Wilson [1993], Ausubel, Cramton, and Deneckere [2002], and Serrano [2008], while for surveys of the auction literature see McAfee and McMillan [1987] and Milgrom [1989]. 
later that require one party to abandon current negotiations before beginning talks with a new potential trading partner, or that consider exogenously specified outside options rather than endogenously determined ones. Analyses of auctions focus on multilateral settings, but auctions lack the communication and interplay inherent to multilateral negotiations.

Incomplete information is an important component of multilateral negotiations' strategic complexity, so in this paper I dispense with it to investigate whether existing models of bilateral negotiations with complete information can be usefully extended to accommodate multilateral negotiations. In Section 3 I describe related research that evaluates similar issues.

In Section 2 I develop an infinite-horizon alternating-offers model of multilateral negotiations that applies in numerous settings such as those described earlier, but for concreteness I consider a buyer negotiating simultaneously with several sellers. The buyer wishes to trade with only one seller, and trade with different sellers can generate different amounts of surplus to be split. In some cases rival sellers constrain the terms of trade to the buyer's benefit, but in others they are irrelevant to the negotiated outcome. The basic model naturally extends the bilateral negotiation model from Rubinstein [1982], and it illustrates how negotiated outcomes are affected by introducing additional sellers into a bilateral setting, by the similarity of sellers in terms of available surplus, and by the parties' relative bargaining strengths. One important and unexpected finding is that the buyer can be better off when it becomes less patient in multilateral negotiations, which contrasts sharply with the effect of impatience in bilateral negotiations.

In Section 4 I extend the basic model to evaluate the buyer's choice of conducting procurement via multilateral negotiations or an auction, which provides empirical predictions about the important issue of institutional choice. I find that the buyer tends to prefer negotiations when the number of sellers is small, when the sellers' products are distinct or their production costs are quite different, and when sellers face entry costs that are sufficiently low. One striking finding when sellers incur entry costs is that the buyer's preferred procurement mechanism can change multiple times within small ranges of those costs, which provides one explanation for the coexistence of auctions and multilateral negotiations across apparently similar buyers in narrowly defined markets.

More generally the model provides a tractable foundation for analyzing strategic problems in settings featuring multilateral negotiations, including investment, product design, mergers, hold-up, dual-sourcing, entry, and collusion. Section 5 describes some of those future research possibilities and provides concluding remarks, while the Appendix contains all proofs.

\section{The Basic Model of Multilateral Negotiations}

Consider a buyer that wishes to trade with at most one of $N$ sellers. Trade between the buyer and seller $i$ yields a commonly known surplus $V_{i} \geq 0$ to be split between the two parties, where $V_{1}>0$ and the sellers are indexed so that $V_{1} \geq V_{2} \geq \cdots \geq V_{N}$. The buyer and each seller $i$ have instantaneous rates of time preference $r_{B}>0$ and $r_{i}>0$. Unlike the $V_{i}$, the ranking of the $r_{i}$ across sellers is not tied to the index $i$.

Trade is conducted as follows, where time is measured in discrete periods $t \in\{0,1,2, \ldots\}$ that are of length $\Delta>0$. In even-numbered period $t \in\{0,2,4, \ldots\}$ each seller $i$ makes a proposal $\left(s_{i, t}, V_{i}-s_{i, t}\right) \in\left[0, V_{i}\right]^{2}$ to the buyer that specifies the amount $s_{i, t}$ of the surplus $V_{i}$ that seller $i$ demands for itself, with the remainder $V_{i}-s_{i, t}$ that it offers to the buyer. The proposals are made simultaneously and are revealed publicly when received by the buyer, after which the buyer decides whether to accept one of the proposals. If the buyer accepts one of the proposals, then the negotiations conclude. If the buyer rejects all of the proposals, then 
in odd-numbered period $t+1 \in\{1,3,5, \ldots\}$ the buyer makes proposals $\left(b_{i, t+1}, V_{i}-b_{i, t+1}\right) \in\left[0, V_{i}\right]^{2}$ to each seller $i$ that specify the amount $b_{i, t+1}$ of the surplus $V_{i}$ that the buyer demands for itself, with the remainder $V_{i}-b_{i, t+1}$ that it offers to seller $i$. The proposals are made simultaneously and are revealed publicly when received by the sellers, after which the sellers simultaneously decide whether to accept their respective proposals. From the set of accepted proposals the buyer decides which transaction, if any, to consummate. If the buyer trades with a seller that accepted its proposal, then the negotiations conclude. If no transaction occurs, then play continues to the next period.

A transaction that occurs in even-numbered period $t$ between the buyer and seller $i$ yields them respective payoffs $\left(V_{i}-s_{i, t}\right) e^{-r_{B} t \Delta}$ and $s_{i, t} e^{-r_{i} t \Delta}$, while a transaction that occurs in odd-numbered period $t$ between the buyer and seller $i$ yields them respective payoffs $b_{i, t} e^{-r_{B} t \Delta}$ and $\left(V_{i}-b_{i, t}\right) e^{-r_{i} t \Delta}$. Losing sellers' payoffs are 0 . If no transaction occurs in any period, then each party's payoff is 0 . For notational convenience define $\delta_{k} \equiv e^{-r_{k} \Delta}$, where $\delta_{k} \in(0,1)$ is player $k$ 's discount factor, for $k \in\{B, 1,2, \ldots, N\}$.

Three issues must be clarified regarding the acceptance of proposals. First, I allow the buyer not to consummate any transaction even if one or more sellers have accepted a proposal from the buyer. As will become apparent later, this assumption prevents the buyer from extracting the entire surplus $V_{1}$ from seller 1 by committing to engage in unfavorable trades. Second, in some period the buyer might accept one of multiple proposals that give it the same payoff. If so, I assume that from those proposals the buyer accepts the one from the seller with the lowest index. Third, in some period several sellers might accept the buyer's proposal. If trade occurs in such an instance, and if multiple proposals accepted by sellers give the buyer its highest payoff, I assume that from those proposals the buyer trades with the seller having the lowest index. The latter two tie-breaking assumptions address an equilibrium existence issue caused by an "openness" problem that arises because the players' allowable demands and offers are drawn from continuous sets.

The preceding model extends the bilateral negotiation model in Rubinstein [1982] by allowing one buyer to negotiate simultaneously with multiple sellers. The assumptions about proposal acceptance and the public nature of the proposals keep the model close in spirit to Rubinstein's model, while allowing for the multilateral aspect.

The players' strategies consist of proposals and accept/reject decisions at every decision point, all of which can depend on all prior moves that led to a specific point in the game. I solve for the game's pure strategy subgame perfect Nash equilibria (SPNE), and for simplicity I focus on stationary SPNE outcomes: SPNE outcomes supported by strategies for which each player $k$ receives the payoff $\pi_{k}^{b o}$ in all subgames that begin with the buyer making offers, and receives the payoff $\pi_{k}^{s o}$ in all subgames that begin with sellers making offers. ${ }^{2}$

I characterize this game's stationary SPNE outcomes by modifying the approach pioneered by Shaked and Sutton [1984] for solving the bilateral negotiation model from Rubinstein [1982]. Their method uses four variables. The first two variables are $\underline{\pi}_{B}$ and $\bar{\pi}_{B}$, which are the infimum and supremum of the set of the buyer's SPNE payoffs, for SPNE in subgames beginning with offers from the buyer. The second two variables are $\underline{\pi}_{1}$ and $\bar{\pi}_{1}$, which are the infimum and supremum of the set of seller 1's SPNE payoffs, for SPNE in subgames beginning with offers from the seller.

Shaked and Sutton [1984] characterize the extremal SPNE payoffs by demonstrating that the following

\footnotetext{
${ }^{2}$ Characterizing all SPNE outcomes has proven to be difficult. It appears that the stationary SPNE outcomes are the unique SPNE outcomes for three of the four parameter ranges listed in Theorem 1. In the fourth it appears there are multiple SPNE outcomes. I have characterized some of them, but have been unable to establish I have characterized all of them.
} 
four constraints must hold.

$$
\underline{\pi}_{B} \geq V_{1}-\delta_{1} \bar{\pi}_{1} \quad \bar{\pi}_{B} \leq V_{1}-\delta_{1} \underline{\pi}_{1} \quad \underline{\pi}_{1} \geq V_{1}-\delta_{B} \bar{\pi}_{B} \quad \bar{\pi}_{1} \leq V_{1}-\delta_{B} \underline{\pi}_{B}
$$

Roughly speaking, the first and third constraints tell a negotiator, "When you are making offers, you need not give too much." The second and fourth tell a negotiator, "When you are making offers, you cannot take too much." Manipulating these constraints reveals that each must hold with equality, and that

$$
\underline{\pi}_{B}=\bar{\pi}_{B}=\left(\frac{1-\delta_{1}}{1-\delta_{1} \delta_{B}}\right) V_{1} \quad \text { and } \quad \underline{\pi}_{1}=\bar{\pi}_{1}=\left(\frac{1-\delta_{B}}{1-\delta_{1} \delta_{B}}\right) V_{1} .
$$

Having established the SPNE payoffs are unique, one can show there is a unique SPNE.

The stationary SPNE outcomes with multilateral negotiations are derived by recognizing that versions of the preceding constraints continue to hold, except in particular circumstances in which the credible prospect of trading with seller 2 requires modifying one or more of the constraints. In some cases the modifications involve introducing an even tighter constraint, and in others involve replacing a constraint with a looser one. Theorem 1 reveals that trade in any subgame occurs between the buyer and seller 1 in the subgame's initial period.

Theorem 1 In subgames that begin with the buyer making offers, in all stationary SPNE outcomes the payoffs for the buyer and seller 1 are

$$
\begin{array}{llll}
\pi_{B}^{b o}=\left(\frac{1-\delta_{1}}{1-\delta_{1} \delta_{B}}\right) V_{1} & \text { and } & \pi_{1}^{b o}=\delta_{1}\left(\frac{1-\delta_{B}}{1-\delta_{1} \delta_{B}}\right) V_{1} & \text { if } V_{2} \in\left[0, \delta_{B}^{2}\left(\frac{1-\delta_{1}}{1-\delta_{1} \delta_{B}}\right) V_{1}\right) \\
\pi_{B}^{b o}=\frac{V_{2}}{\delta_{B}^{2}} & \text { and } & \pi_{1}^{b o}=V_{1}-\frac{V_{2}}{\delta_{B}^{2}} & \text { if } V_{2} \in\left[\delta_{B}^{2}\left(\frac{1-\delta_{1}}{1-\delta_{1} \delta_{B}}\right) V_{1}, \delta_{B}^{2} V_{1}\right] \\
\pi_{B}^{b o}=V_{1} & \text { and } & \pi_{1}^{b o}=0 & \text { if } V_{2} \in\left(\delta_{B}^{2} V_{1}, \delta_{B} V_{1}\right) \\
\pi_{B}^{b o}=V_{1} & \text { and } & \pi_{1}^{b o}=0 & \text { if } V_{2} \in\left[\delta_{B} V_{1}, V_{1}\right] .
\end{array}
$$

In subgames that begin with sellers making offers, in all stationary SPNE outcomes the payoffs for the buyer and seller 1 are

$$
\begin{array}{llll}
\pi_{B}^{s o}=\delta_{B}\left(\frac{1-\delta_{1}}{1-\delta_{1} \delta_{B}}\right) V_{1} & \text { and } & \pi_{1}^{s o}=\left(\frac{1-\delta_{B}}{1-\delta_{1} \delta_{B}}\right) V_{1} & \text { if } V_{2} \in\left[0, \delta_{B}^{2}\left(\frac{1-\delta_{1}}{1-\delta_{1} \delta_{B}}\right) V_{1}\right) \\
\pi_{B}^{s o}=\frac{V_{2}}{\delta_{B}} & \text { and } & \pi_{1}^{s o}=V_{1}-\frac{V_{2}}{\delta_{B}} & \text { if } V_{2} \in\left[\delta_{B}^{2}\left(\frac{1-\delta_{1}}{1-\delta_{1} \delta_{B}}\right) V_{1}, \delta_{B}^{2} V_{1}\right] \\
\pi_{B}^{s o}=\delta_{B} V_{1} & \text { and } & \pi_{1}^{s o}=\left(1-\delta_{B}\right) V_{1} & \text { if } V_{2} \in\left(\delta_{B}^{2} V_{1}, \delta_{B} V_{1}\right) \\
\pi_{B}^{s o}=V_{2} & \text { and } & \pi_{1}^{s o}=V_{1}-V_{2} & \text { if } V_{2} \in\left[\delta_{B} V_{1}, V_{1}\right] .
\end{array}
$$

The unique stationary SPNE payoffs with multilateral negotiations are more complex than the unique SPNE payoffs with bilateral negotiations, but the derivations of both outcomes share the fundamental concept that a party formulating a proposal must explicitly consider its counterpart's payoff from rejecting that proposal. With bilateral negotiations the counterpart's payoff from rejecting corresponds to incurring delay and making a proposal next period. With multilateral negotiations there is the additional influence of the buyer's ability to trade with seller 2, which in several instances the buyer can use to dramatic effect.

Theorem 1's characterization of the buyer's and seller 1's stationary SPNE payoffs demonstrates that whether seller 2 affects the negotiations depends on the relationship among $V_{1}, V_{2}, \delta_{1}$, and $\delta_{B}$. Seller 2 is more likely to affect the negotiations as $V_{1}$ decreases or $V_{2}$ increases, because those changes make sellers 1 
and 2 closer competitors in terms of what surplus they can offer the buyer. Seller 2 also is more likely to affect the negotiations as $\delta_{1}$ increases or $\delta_{B}$ decreases, because those changes decrease the buyer's relative bargaining strength, and hence the portion of $V_{1}$ it would obtain if seller 2 were not present. Consequently, the surplus available from seller 2 is more likely to affect the negotiated outcome.

It is instructive to focus on the novel impact of adding additional sellers to a bilateral setting, which reveals that for low values of $V_{2}$ the multilateral negotiations' stationary SPNE payoffs are equivalent to those from Rubinstein's model of bilateral negotiations. Sellers 2 through $N$ are strategically irrelevant to the negotiated outcome when the surpluses available from them are so low, so the negotiations between the buyer and seller 1 proceed as if those other sellers were not present. Figure 1 illustrates this range of $V_{2}$, by plotting the buyer's SPNE payoffs in subgames beginning with offers from the buyer (panel (a)), and in subgames beginning with offers from the sellers (panel (b)). As $V_{2}$ increases from 0 , for a range of $V_{2}$ the buyer's SPNE payoffs remain fixed at their levels from bilateral negotiations.

\section{Figure 1 Here}

For intermediate values of $V_{2}$ the multilateral negotiations have an unusual feature: when the sellers make offers, the buyer's payoff equals the net present value of what it expects to get next period $\left(\frac{V_{2}}{\delta_{B}}\right.$ versus getting $\frac{V_{2}}{\delta_{B}^{2}}$ next period). Offering a player just enough to induce trade is a typical feature in bilateral negotiations. However, when the buyer makes offers, seller 1's payoff is less than the net present value of what it expects to get next period. Instead, seller 1's payoff is constrained by the requirement that the buyer not prefer to trade today with seller 2, which is equivalent to the net present value of the buyer's payoff from waiting until the next period ( $V_{2}$ versus getting $\frac{V_{2}}{\delta_{B}}$ next period).

For high values of $V_{2}$ the multilateral negotiations' stationary SPNE outcome features the buyer extracting the entire surplus $V_{1}$ from seller 1 when the buyer makes offers to the sellers. This is possible because it is credible for the buyer to trade with seller 2 if seller 1 refuses the buyer's offer. Hence, it is as if the buyer can make a take-it-or-leave-it offer to seller 1, which enables the extraction of the entire surplus $V_{1}$. For such values of $V_{2}$, Figure 1 (b) shows that differences in the SPNE outcome emerge for different $V_{2}$ based on what seller 1 must offer when the sellers make offers to the buyer. When $\delta_{B} V_{1}>V_{2}$, the buyer's payoff is $\delta_{B} V_{1}$ : seller 1 offers the buyer just enough not to reject all offers and get $V_{1}$ next period, and trade with seller 2 is not a credible threat. When $\delta_{B} V_{1}<V_{2}$, the buyer's payoff is $V_{2}$ : seller 1 offers the buyer just enough not to trade with seller 2 , which is a credible threat rather than rejecting all offers and getting $V_{1}$ next period.

At this point it is worth returning to the modeling assumption that the buyer is not committed to trade whenever at least one seller accepts the buyer's proposal. If the buyer were so committed, then with its proposals the buyer always could extract $V_{1}$ from seller 1 . To see why, imagine the buyer offered $\epsilon>0$ to sellers 1 and 2. In any equilibrium, seller 2 accepts whenever seller 1 rejects, which forces seller 1 to accept rather than receive a payoff of 0 . Letting $\epsilon \rightarrow 0$ completes the argument, which illustrates that such commitment effectively allows the buyer to always make seller 1 a take-it-or-leave-it offer. The problem is that the buyer might prefer not to trade with seller 2 , if by doing so the buyer's payoff $V_{2}-\epsilon$ is less than what the buyer would receive if the negotiations continued to the next period. In the high range of $V_{2}$ described in the preceding paragraph, the buyer actually prefers trading today with seller 2 rather than letting the negotiations continue, so there is no sense in which the buyer has committed to a trade it prefers to reject.

Figure 2 reveals that the equilibrium payoffs in Theorem 1 have some unusual properties, relative to the conventional wisdom derived from bilateral negotiation models. As a function of the discount factor $\delta_{B}$, the 
figure plots the buyer's stationary SPNE payoff in multilateral negotiations (the solid line) and the buyer's SPNE payoff in bilateral negotiations (the dashed line).

\section{Figure 2 Here}

Panel (a) considers subgames that begin with offers by the buyer. When the buyer is sufficiently impatient, with its offers it extracts the entire surplus $V_{1}$ from seller 1 . This feat is possible because the buyer is so impatient that it can credibly commit to trade this period with seller 2 if seller 1 rejects the buyer's offer. ${ }^{3}$ For intermediate values of $\delta_{B}$ the buyer does worse when it becomes more patient, which contrasts with the conventional wisdom about the effect of patience on bargaining outcomes. Finally, for sufficiently high values of $\delta_{B}$ the buyer's payoff is the same in multilateral and bilateral negotiations, because the buyer is sufficiently patient that it can protect its interests without resorting to the threat of trading with seller 2. Note that the buyer's payoff at the beginning of this range of $\delta_{B}$ is strictly less than its payoff for very low values of $\delta_{B}$. Only as $\delta_{B}$ approaches 1 does the buyer's payoff return to the same level as when $\delta_{B}$ was small.

Panel (b) considers subgames that begin with offers by the sellers. For low values of $\delta_{B}$ seller 1 anticipates that the buyer will extract the entire surplus $V_{1}$ if the negotiations reach the next period. To end the negotiations in this period and get a positive payoff, seller 1 therefore must offer the buyer at least $\delta_{B} V_{1}$. However, if $V_{2}>\delta_{B} V_{1}$, then the threat from seller 2 requires seller 1 to ensure that the buyer's payoff is $V_{2}$. Hence, for low values of $\delta_{B}$ the buyer's payoff is $V_{2}$, and eventually switches to $\delta_{B} V_{1}$ as $\delta_{B}$ increases. Once again, for intermediate values of $\delta_{B}$ the buyer does worse when it becomes more patient, and for high values of $\delta_{B}$ the buyer's payoff is the same in multilateral and bilateral negotiations.

Corollary 1 evaluates the stationary SPNE outcomes from Theorem 1 as the time period between offers $\Delta \rightarrow 0$. Muthoo [1999, Ch. 3.2] suggests this limiting case is the appropriate one to consider, because a party making a counteroffer has incentives to do so quickly to reduce its cost of delay. The limiting values of the payoffs as $\Delta \rightarrow 0$ also do not depend on who makes the initial offers, so there is no first-mover advantage in the limit. Letting $\Delta \rightarrow 0$ simplifies matters by eliminating two of the relevant ranges for $V_{2}$ from Theorem 1 , and the stationary SPNE payoffs have an intuitively appealing form.

Corollary 1 As the time period between offers $\Delta \rightarrow 0$, in all stationary SPNE outcomes in all subgames, the payoffs for the buyer and seller 1 approach

$$
\begin{aligned}
& \pi_{B}^{*}=\left(\frac{r_{1}}{r_{1}+r_{B}}\right) V_{1} \quad \text { and } \quad \pi_{1}^{*}=\left(\frac{r_{B}}{r_{1}+r_{B}}\right) V_{1} \quad \text { if } V_{2} \in\left[0,\left(\frac{r_{1}}{r_{1}+r_{B}}\right) V_{1}\right) \\
& \pi_{B}^{*}=V_{2} \quad \text { and } \pi_{1}^{*}=V_{1}-V_{2} \quad \text { if } V_{2} \in\left[\left(\frac{r_{1}}{r_{1}+r_{B}}\right) V_{1}, V_{1}\right] \text {. }
\end{aligned}
$$

These can be written more compactly as

$$
\pi_{B}^{*}=\max \left[V_{2},\left(\frac{r_{1}}{r_{1}+r_{B}}\right) V_{1}\right] \quad \text { and } \quad \pi_{1}^{*}=\min \left[V_{1}-V_{2},\left(\frac{r_{B}}{r_{1}+r_{B}}\right) V_{1}\right] .
$$

In the limit, a player's stationary SPNE payoff in a subgame does not depend on whether the buyer or the sellers are making offers.

\footnotetext{
${ }^{3}$ As mentioned earlier, if the game's structure required the buyer always to trade according to its best accepted offer, then the buyer could always extract $V_{1}$ when making offers: Seller 2 will accept any offer giving it a strictly positive payoff whenever seller 1 rejects, so seller 1 could never reject an extremely unfavorable offer.
} 
Corollary 1 completely characterizes the buyer's and seller 1's payoffs in all stationary SPNE outcomes as the time period between offers $\Delta \rightarrow 0$. In those SPNE the division of the maximum surplus $V_{1}$ depends on whether seller 2 constrains the negotiations. If $V_{2}$ is large enough to constrain the negotiations, then the buyer's payoff is higher than it would be if seller 2 were not present, and seller 1's payoff is lower. This is direct evidence of the benefit to the buyer of bringing an additional seller into an initially bilateral setting. If $V_{2}$ is small enough not to constrain the negotiations, then the buyer's and seller 1's payoffs are identical to those in Rubinstein's model. In fact, setting $V_{2}=0$ gives Rubinstein's bilateral negotiation model as a special case.

Comparative statics regarding the players' stationary SPNE payoffs, with respect to the discount rates, also depend on whether seller 2 constrains the negotiations. If $V_{2}$ is large enough to constrain the negotiations, then changes in the buyer's and seller 1's discount rates do not affect the parties' payoffs. For example, one special case of seller 2 constraining the negotiations is when $V_{1}=V_{2}$, in which case the buyer gets all of the surplus and the discount rates are irrelevant. If $V_{2}$ is small enough not to constrain the negotiations, then standard comparative statics emerge: as the buyer becomes more patient it does strictly better in the negotiations and seller 1 does strictly worse, while the reverse holds as seller 1 becomes more patient.

One thing to notice from the results in Theorem 1 and Corollary 1 is that seller 2's patience is irrelevant to the negotiated outcome, even though the surplus $V_{2}$ available from seller 2 might play a role. All that matters is that seller 2 is ready to give the entire surplus $V_{2}$ to the buyer when making an offer, and is willing to accept any offer from the buyer. Therefore, seller 2's patience is irrelevant because its behavior is driven entirely by consideration of its payoff in the current period.

In Section 4 I use the unique limiting values of the stationary SPNE payoffs $\pi_{B}^{*}$ and $\pi_{1}^{*}$ to evaluate the buyer's choice of conducting procurement via multilateral negotiations or an auction. The limiting case seems appropriate given the points raised immediately prior to Corollary 1, and the unique stationary SPNE outcome seems to be natural one to consider. In Section $4 \mathrm{I}$ also exploit the fact that $\pi_{B}^{*}$ and $\pi_{1}^{*}$ can be written as functions of the ratio of discount rates, $\frac{r_{B}}{r_{1}}$, which reflects the importance of relative bargaining strength, rather than absolute. Before proceeding to that analysis, I place this new model in context.

\section{Relationship to Prior Research}

Earlier research considers various extensions of bilateral negotiation models to address the idea of a buyer negotiating with multiple sellers. Below I describe representative examples that use models or ask questions similar to mine, for the purpose of comparing their structure and predictions with the model described in Theorem $1 .^{4,5}$ The models that explicitly incorporate multiple sellers assume the sellers are identical, which conforms to the special case of my model in which $V_{1}=V_{2}=\cdots=V_{N}$.

Shaked and Sutton [1984] model bilateral negotiations with complete information and alternating offers. The buyer bargains with one seller at a time, but can switch to a different seller after some commonly known length of time. Offers from one seller are void upon switching to another seller. The authors find that

\footnotetext{
${ }^{4}$ Other papers that share some similarities include Reinganum and Daughety [1991, 1992], Hendon and Tranaes [1991], Muthoo [1995], Chatterjee and Dutta [1998], and Marx and Shaffer [2010]. Two recent papers that consider multilateral negotiations with incomplete information are McAdams and Schwarz [2007] and Thomas [2011]. See Thomas [2011] for references to additional papers with incomplete information that consider some aspects of the multilateral negotiation problem analyzed there.

${ }^{5}$ For clarity's sake it is worth mentioning that these models and mine address an exchange problem that is distinct from the multilateral bargaining considered by authors such as Krishna and Serrano [1996], in which multiple players bargain to split one joint surplus. That setting emphasizes different issues and is inherently different from the one I am considering.
} 
the presence of another seller constitutes a credible threat that permits the buyer to obtain greater surplus than if switching were impossible. The outcome as the switching delay approaches the length of a bargaining period is identical to the outcome if the buyer instead conducted a first-price auction between the two sellers. My model lets the buyer bargain simultaneously with multiple sellers, and the negotiations and an auction have the same outcome only if seller 2 constrains the negotiated outcome. ${ }^{6}$

Binmore, Shaked, and Sutton [1989] modify Rubinstein's bilateral negotiation model so that the buyer can take up a commonly known and exogenously specified outside option only when it rejects the seller's offer, while Muthoo [1999, Ch. 5.6] assumes the buyer can take up its outside option only after its offer is rejected. Shaked [1994] allows the buyer to take up its outside option after either party rejects, but in each period Nature randomly determines which party makes an offer. All three models' equilibrium payoffs share similarities with those in Theorem 1 if the payoff from the exogenous outside option equals $V_{2}$. Despite the similarity of the modeling approaches, there are at least two reasons to prefer Section 2's model of endogenous outside options. First, the latter model illustrates how the outside option is determined, that the payoff from the outside option represents the entire surplus available from that alternative trade, and that the patience of the alternative trading partner is irrelevant. Second, applications like those in Sections 4 and 5 make sense only if the outside options result from decisions by strategic actors.

Vincent [1992] considers simultaneous negotiations by adding an additional seller to a bilateral negotiation setting with complete information in which only the sellers make offers. He finds that the buyer might not secure all gains from trade, due to the sellers' ability to support collusive equilibria through the prospect of potentially an infinite number of bargaining periods. My model differs from his by allowing both the buyer and the sellers to make offers. This crucial distinction enables a seller to deviate profitably from collusive behavior by accepting an offer that ends the game, thereby avoiding retaliatory future punishment from rival sellers.

Finally, Chatterjee and Lee [1998] model bilateral negotiations with complete information in which the buyer can hold an offer from one seller while it incurs a cost to acquire an offer from another seller. The important distinction from my model is that the authors assume the competing offer is a draw from a commonly known and exogenously specified probability distribution, rather than being the outcome of strategic interaction with another seller.

\section{Multilateral Negotiations Versus Auctions}

In practice the buyer must choose a method for conducting procurement, and the reality of such decisions is one reason economists emphasize understanding the performance of different voluntary exchange mechanisms. ${ }^{7}$ In this section I use the unique stationary SPNE payoffs from Corollary 1 to directly compare two commonly used procurement mechanisms: multilateral negotiations and auctions.

Bulow and Klemperer [1996] analyze a buyer's choice between negotiations and auctions in a setting with homogeneous products and incomplete information about sellers' costs. They illustrate circumstances in which a buyer prefers a simple second-price auction with $N+1$ sellers to an optimal mechanism with $N$ sellers. The authors do not analyze a specific negotiation protocol, but let the optimal mechanism provide an upper bound on the buyer's payoff from negotiating. Their results suggest that attracting more sellers

\footnotetext{
${ }^{6} \mathrm{As}$ it would in the special case of my model that conforms to theirs, in which $V_{1}=V_{2}=\cdots=V_{N}$.

${ }^{7}$ For example, consider how the work by Chamberlin [1948] and Smith [1962] spurred research on the importance of institutions in determining economic outcomes.
} 
can be more important than increasing the buyer's bargaining strength. ${ }^{8,9}$

Prompted in part by the observation that multilateral negotiations and auctions are used by apparently similar buyers in the same market, Thomas and Wilson [2002, 2005, 2012] use experiments to compare both exchange mechanisms. In settings with incomplete information they consider first-price and secondprice auctions, homogeneous and differentiated products, and negotiations that differ in the buyer's ability to provide verifiable information to a seller about offers from rival sellers. The authors find that the mechanisms' outcomes are similar, and in some cases are statistically indistinguishable. They conduct experiments because no formally solved models were available that considered the sort of negotiations in which they were interested.

I evaluate the buyer's choice by extending Section 2's basic model in ways that make the institutional comparison nontrivial; it will be evident that in the basic model the buyer weakly prefers multilateral negotiations. This section's goal is to provide some simple extensions that yield theoretical and empirical insights, and that also suggest more complex or comprehensive extensions.

Three phases comprise the extended game: The surplus-determination phase consists of a move by Nature that determines the $V_{i}$ draws according to some commonly known probability distribution. The planning phase consists of three choices that occur in a specific order: First, the buyer chooses publicly between conducting multilateral negotiations or a first-price auction. Second, the buyer chooses publicly which of the $N$ sellers to invite to participate. Third, the invited sellers make simultaneous and public decisions whether to participate. The procurement phase consists of competition amongst the participating sellers. That competition is conducted via either the multilateral negotiations described in Section 2, or a first-price auction in which each seller $i$ makes a simultaneous price offer $p_{i} \in\left[0, V_{i}\right]$ to the buyer. The buyer purchases from the seller whose offer gives the buyer its highest payoff, $V_{i}-p_{i}$, with ties handled in the same fashion as in the multilateral negotiations. It is straightforward to establish that the buyer's payoff in a first-price auction is the second-highest surplus from the set of participating sellers. ${ }^{10}$

The procurement phase occurs last in the extensions I consider below, but either the surplus-determination or the planning phase can occur first. The order of those two phases determines whether the buyer and sellers make their planning choices after or before they know the available surpluses.

\subsection{Institutional Choice with Fixed $V_{i}$}

Consider the case in which the surplus-determination phase occurs before the planning phase, and in which the buyer incurs an incremental cost of conducting multilateral negotiations versus an auction, $C^{m l n} \in \mathbb{R}$. I assume the buyer invites all sellers, and that all invited sellers participate, because participation is costless. The only substantive difference from the basic model is the inclusion of the cost $C^{m l n} .{ }^{11}$

From Corollary 1 the buyer's payoff in multilateral negotiations is

$$
\pi_{B}^{m l n}=\pi_{B}^{*}-C^{m l n}=\max \left[V_{2},\left(\frac{r_{1}}{r_{1}+r_{B}}\right) V_{1}\right]-C^{m l n},
$$

\footnotetext{
${ }^{8}$ I do not address this issue in the analysis to follow, but one could do so. It is straightforward to generate examples that give the opposite conclusion, which suggests the importance of incomplete information in making such comparisons.

${ }^{9}$ More recently, Bulow and Klemperer [2009] consider this choice when the mechanisms involve costly entry but differ in their timing. Their auctions involve simultaneous entry decisions followed by price competition. Their negotiations involve sequential entry by sellers, where later sellers enter only if trade with earlier sellers is insufficiently attractive.

${ }^{10}$ For example, see Kim and Che [2004]. In this complete information setting the buyer's payoff also is the same in a Dutch, English, or second-price auction.

${ }^{11}$ One also could include costs incurred by the buyer for each seller that participates. In Subsection 4.3 I consider costs incurred by each seller that participates.
} 
while its payoff in a first-price auction is

$$
\pi_{B}^{f p a}=V_{2}
$$

The following result is straightforward to obtain.

Proposition 1 Consider the case in which the surplus-determination phase precedes the planning phase. The buyer strictly prefers multilateral negotiations if and only if

$$
C^{m l n}<\max \left[0,\left(\frac{r_{1}}{r_{1}+r_{B}}\right) V_{1}-V_{2}\right]
$$

The buyer's relative preference for multilateral negotiations intensifies as $C^{m l n}$ decreases, as $V_{1}$ increases or $V_{2}$ decreases, and as $\frac{r_{B}}{r_{1}}$ decreases.

This simple extension of the basic model illustrates what factors make the buyer more inclined to use multilateral negotiations. Figure 3 shows the buyer's payoff in both institutions, as a function of the ratio of discount rates $\frac{r_{B}}{r_{1}}$, for some positive incremental cost of conducting multilateral negotiations, $C^{m l n}$. Each panel shows a parameter change that increases the range of $\frac{r_{B}}{r_{1}}$ for which the buyer prefers multilateral negotiations. Panel (a) shows that decreasing $C^{m l n}$ has the obvious effect of increasing multilateral negotiations' attractiveness, because they become cheaper to conduct relative to an auction. Panel (b) shows that increasing $V_{1}$ increases the buyer's payoff from multilateral negotiations while leaving unchanged its payoff from a first-price auction. Increasing $V_{1}$ in multilateral negotiations increases the amount of surplus to be split between the buyer and seller 1, but in a first-price auction has no effect because the buyer's payoff is determined solely by $V_{2}$. Panel (c) shows that decreasing $V_{2}$ lowers the buyer's payoff in both institutions, but to different extents. In a first-price auction decreasing $V_{2}$ reduces the buyer's payoff one-for-one, because the buyer's payoff is $V_{2}$. In multilateral negotiations decreasing $V_{2}$ leaves the buyer's payoff unchanged in the original instances in which seller 2 is irrelevant to the negotiated outcome, decreases the buyer's payoff less than one-for-one in a range of cases in which seller 2 initially constrained the negotiations, and otherwise decreases the buyer's payoff one-for-one. The net effect makes multilateral negotiations more attractive for a larger range of relative discount rates, $\frac{r_{B}}{r_{1}}$.

\section{Figure 3 Here}

Finally, each panel of Figure 3 illustrates that multilateral negotiations are relatively more attractive as $\frac{r_{B}}{r_{1}}$ decreases, which is a crucial element of the buyer's choice between multilateral negotiations and an auction. Reducing $\frac{r_{B}}{r_{1}}$ reflects an increase in the buyer's bargaining strength relative to seller 1, and by conducting an auction the buyer forgoes any bargaining advantage it might have.

\subsection{Institutional Choice with Random $V_{i}$ and Costless Participation}

Now consider the case in which the planning phase precedes the surplus-determination phase. The available surpluses are unknown when the buyer chooses the procurement mechanism and which sellers to invite, and when the sellers make their participation decisions. For simplicity I assume the $V_{i}$ are independently and identically drawn from $U[0,1]$. I also assume $r_{i}=r_{S}$ for each seller $i$, because otherwise the details of the institutional choice depend in a straightforward but tedious way on the values of the $r_{i}$ and the realized $V_{i}$. Finally, I assume the buyer invites all sellers, and that all invited sellers participate, because participation is costless. 
The buyer's payoff in multilateral negotiations depends on the highest and second-highest realized $V_{i}$, while its payoff in a first-price auction depends on the second-highest realized $V_{i}$. To calculate the buyer's expected payoffs one therefore must consider distributions of the highest and second-highest order statistics of $N$ draws from $U[0,1]$. Denoting those order statistics by $V_{(1)}$ and $V_{(2)}$, the distribution of $V_{(1)}$ is

$$
G_{1}(v) \equiv \operatorname{Pr}\left(V_{(1)} \leq v\right)=v^{N}
$$

the distribution of $V_{(2)}$ conditional on the value of $V_{(1)}$ is

$$
G_{2}(v \mid w) \equiv \operatorname{Pr}\left(V_{(2)} \leq v \mid V_{(1)}=w\right)=\frac{v^{N-1}}{w^{N-1}}
$$

and the unconditional distribution of $V_{(2)}$ is

$$
G_{2}(v) \equiv \operatorname{Pr}\left(V_{(2)} \leq v\right)=v^{N}+N(1-v) v^{N-1} .
$$

Corollary 1 gives the buyer's payoff for any particular realization of the $V_{i}$, so the buyer's expected payoff in multilateral negotiations is

$$
\begin{aligned}
\pi_{B}^{m l n} & =\left[\int_{0}^{1}\left\{\int_{0}^{v_{(1)}} \max \left[v_{(2)},\left(\frac{r_{S}}{r_{S}+r_{B}}\right) v_{(1)}\right] G_{2}^{\prime}\left(v_{(2)} \mid v_{(1)}\right) d v_{(2)}\right\} G_{1}^{\prime}\left(v_{(1)}\right) d v_{(1)}\right]-C^{m l n} \\
& =\frac{N-1+\left(\frac{r_{S}}{r_{S}+r_{B}}\right)^{N}}{N+1}-C^{m l n}
\end{aligned}
$$

Similarly, the buyer's expected payoff in a first-price auction is

$$
\begin{aligned}
\pi_{B}^{f p a} & =\int_{0}^{1} v_{(2)} G_{2}^{\prime}\left(v_{(2)}\right) d v_{(2)} \\
& =\frac{N-1}{N+1} .
\end{aligned}
$$

Proposition 2 Consider the case in which the planning phase precedes the surplus-determination phase, and the $V_{i}$ are iid draws from $U[0,1]$. The buyer strictly prefers multilateral negotiations if and only if

$$
C^{m l n}<\frac{\left(\frac{r_{S}}{r_{S}+r_{B}}\right)^{N}}{N+1} .
$$

The buyer's relative preference for multilateral negotiations intensifies as $C^{m l n}$ decreases, as $N$ decreases, and as $\frac{r_{B}}{r_{S}}$ decreases.

Proposition 2 illustrates that the buyer tends to prefer multilateral negotiations for low values of $C^{m l n}$, $N$, and $\frac{r_{B}}{r_{S}}$. Decreasing $C^{m l n}$ has the obvious effect of making multilateral negotiations relatively cheaper to conduct. Decreasing $N$ increases the expected difference between the highest and second-highest surpluses. As Corollary 1 demonstrates, as that gap increases it is more likely that negotiations outperform an auction. Likewise, decreasing $\frac{r_{B}}{r_{S}}$ strengthens the buyer's bargaining position, an advantage that is forgone by conducting an auction.

One also can assess how changing the variance of the $V_{i}$ draws affects the buyer's institutional choice, 
say by considering mean-preserving changes in the distribution. A formal analysis is messy, even with the $V_{i}$ uniformly distributed, but the following informal argument demonstrates that increasing the variance increases the relative attractiveness of multilateral negotiations.

Suppose the $V_{i}$ are independently and identically drawn from $U\left[\frac{1}{2}-\theta, \frac{1}{2}+\theta\right]$ for $\theta \in\left[0, \frac{1}{2}\right]$. If $\theta$ is sufficiently small such that $\frac{1}{2}-\theta \geq\left(\frac{r_{S}}{r_{S}+r_{B}}\right)\left(\frac{1}{2}+\theta\right)$, then seller 2 constrains the negotiations for any realizations of the $V_{i}$. That is, even for the highest possible value of $V_{(1)}\left(=\frac{1}{2}+\theta\right)$ and the lowest possible value of $V_{(2)}\left(=\frac{1}{2}-\theta\right), V_{(2)}$ exceeds the buyer's share of $V_{(1)}$ from bilateral negotiations. Consequently, the buyer's expected payoff is the same with multilateral negotiations or an auction, not counting any differential cost of conducting negotiations. ${ }^{12}$ This informal analysis suggests that negotiations are more likely to be used when sellers are more likely to differ in their available surplus, such as when the buyer's tastes tend to be quite distinct for different sellers' products, or when there is significant cost variability across sellers. Multilateral negotiations outperform auctions in such circumstances because the buyer's bargaining ability strongly influences the negotiated outcome, and that ability is wasted by conducting an auction.

\subsection{Institutional Choice with Random $V_{i}$ and Costly Participation}

Finally, consider extending the preceding subsection's analysis by having sellers incur a cost of participating before they learn the $V_{i}$ draws, $C^{\text {entry }} \in \mathbb{R}^{+}$. This cost can reflect opportunity costs of designing prototypes, evaluating production costs, assessing the product's fit with the buyer's preferences, or formulating an initial proposal. I assume $C^{m l n}=0$ to focus attention on the uncertainty when decisions are made.

Costly entry has been considered in other oligopoly models, mainly to determine its effect on prices and welfare. ${ }^{13}$ A common finding is that the buyer might benefit from decreasing the size of the pool of potential entrants, which in my extended model amounts to inviting fewer than $N$ sellers to participate.

As a first step I consider the sellers' participation decisions when the buyer invites all $N$ sellers to participate, for each institution $x \in\{m l n, f p a\}$. Let $\pi_{S}^{x}(n)$ denote a seller's expected payoff from participating in institution $x$ when a total of $n$ sellers participate.

If $C^{\text {entry }}<\pi_{S}^{x}(N)$, then each seller participates with probability 1 because it expects a positive net payoff even if all of its rivals participate. With the $V_{i}$ drawn from $U[0,1]$,

$$
\pi_{S}^{m l n}(N)=\frac{1-\left(\frac{r_{S}}{r_{S}+r_{B}}\right)^{N}}{N(N+1)} \text { and } \pi_{S}^{f p a}(N)=\frac{1}{N(N+1)} .
$$

Because $\pi_{S}^{m l n}(N)<\pi_{S}^{f p a}(N)$, in multilateral negotiations sellers stop participating with probability 1 at a lower value of $C^{\text {entry }}$ than in an auction.

If $C^{\text {entry }}>\pi_{S}^{x}(1)$, then each seller participates with probability 0 because it expects a negative net payoff even if none of its rivals participate. Once again exploiting the Uniform distribution of the $V_{i}$,

$$
\pi_{S}^{m l n}(1)=\left(\frac{r_{B}}{r_{S}+r_{B}}\right)\left(\frac{1}{2}\right) \quad \text { and } \quad \pi_{S}^{f p a}(1)=\frac{1}{2} .
$$

Because $\pi_{S}^{m l n}(1)<\pi_{S}^{f p a}(1)$, in multilateral negotiations sellers stop participating entirely at a lower value of $C^{\text {entry }}$ than in an auction. For later reference note that these values of $C^{\text {entry }}$ are invariant to the number

\footnotetext{
${ }^{12}$ The informal analysis is messy for larger values of $\theta$, because in calculating the buyer's expected payoff one must account for whether the realizations of the $V_{i}$ are such that seller 2 constrains the negotiations.

13 For example, costly entry is examined in a Bertrand setting by Lang and Rosenthal [1991], in a Cournot setting by Dixit and Shapiro [1986], and in an auction setting by Levin and Smith [1994].
} 
of invited sellers, because they are determined solely from a seller's expected payoff when it is the only participating seller.

Finally, if $\pi_{S}^{x}(N) \leq C^{e n t r y} \leq \pi_{S}^{x}(1)$, then I consider strategies such that each seller participates with probability $\rho^{x} \in(0,1)$. The entry probability depends on the number of invited sellers and the value of $C^{\text {entry }}{ }^{14}$ The equilibrium value of $\rho^{x}$ equates a seller's expected payoff from participating and not participating. Specifically, $\rho^{x}$ solves

$$
\left[\sum_{k=0}^{N-1}\left(\begin{array}{c}
N-1 \\
k
\end{array}\right)\left(\rho^{x}\right)^{k}\left(1-\rho^{x}\right)^{n-1-k} \pi_{S}^{x}(k+1)\right]-C^{\text {entry }}=0 .
$$

Once the entry probability is derived, the buyer's expected payoff is

$$
\pi_{B}^{x}=\sum_{k=0}^{N}\left(\begin{array}{c}
N \\
k
\end{array}\right)\left(\rho^{x}\right)^{k}\left(1-\rho^{x}\right)^{n-1-k} \pi_{B}^{x}(k),
$$

where $\pi_{B}^{x}(k)$ denotes the buyer's expected payoff from institution $x$ when a total of $k$ sellers participate.

Even with the simple expressions for $\pi_{B}^{x}(k)$ that precede Proposition 2 (substituting $k$ for $N$ as appropriate), the equilibrium values of $\rho^{x}$ and $\pi_{B}^{x}$ do not have convenient analytic expressions. However, the equilibrium value of $\rho^{x}$ can be solved numerically, from which $\pi_{B}^{x}$ is easily calculated.

Figure 4 reports $\pi_{B}^{m l n}$ and $\pi_{B}^{f p a}$ as a function of $C^{\text {entry }}$, with panels (a)-(c) featuring different numbers of invited sellers. Each panel shows $\pi_{B}^{m l n}$ for three values of $\frac{r_{B}}{r_{S}}$, while $\pi_{B}^{f p a}$ is invariant to the parties' discount rates.

Figure 4 Here

The first insight from Figure 4 is that the buyer strictly prefers multilateral negotiations for low entry costs, and strictly prefers a first-price auction for high entry costs. From Proposition 2 the buyer prefers multilateral negotiations over an auction for any specific number of participants when $C^{m l n}=0$, and both institutions' efficiency implies that the sellers prefer an auction for any specific number of participants. For sufficiently low entry costs, all invited sellers participate in both institutions. Therefore, the buyer prefers multilateral negotiations. As the entry cost increases further, sellers in multilateral negotiations participate less frequently than they do in an auction. The decreased participation harms the buyer directly in the negotiations because with fewer sellers the expected value of the highest surplus declines. Eventually this decline swamps the buyer's advantage from its bargaining ability. This effect is clearly seen in the extreme when $C^{\text {entry }}$ is such that no sellers enter with negotiations, but some sellers might enter with an auction.

Finding that the buyer's preferred procurement method depends on entry costs illustrates an important reason for considering costly entry. Levin and Smith [1994] found no such effects in their analysis of costly entry with different auction formats, because the formats they considered all were revenue equivalent for any particular number of actual entrants. Hence, the sellers' entry probabilities were the same across institutions. In contrast, the fact that payoffs in multilateral negotiations and a first-price auction differ for any specific number of participating sellers causes the buyer's preference to depend on the level of $C^{\text {entry }}$.

The second insight from Figure 4 is that the value of $C^{\text {entry }}$ at which the buyer's institutional choice changes increases as the buyer's relative bargaining strength diminishes. Extreme values of $\frac{r_{B}}{r_{S}}$ illustrate

\footnotetext{
${ }^{14}$ While there exist asymmetric equilibria in which a subset of invited sellers participate with probability 0 , I focus on symmetric equilibria because of the strategic environment's symmetry.
} 
this point clearly. As $\frac{r_{B}}{r_{S}} \rightarrow 0$ the buyer prefers a first-price auction for any $C^{\text {entry }}>0$, because the buyer's overwhelming bargaining ability ensures that no sellers participate if the buyer uses multilateral negotiations. As $\frac{r_{B}}{r_{S}} \rightarrow \infty$ multilateral negotiations and an auction become more similar for any specific number of participating sellers. Hence, the sellers' participation probabilities also get more similar, and the value of $C^{\text {entry }}$ increases at which the buyer's preferred choice changes.

Careful examination of Figure 4 reveals that the buyer's expected payoff is higher with fewer invited sellers, for some values of $C^{\text {entry }}$. This result is consistent with findings mentioned earlier from Lang and Rosenthal [1991] and Levin and Smith [1994], and it stems from the interplay between the number of invited sellers and the invited sellers' probability of participating. One implication of this finding is that the buyer's ability to restrict the number of sellers it invites might eliminate the change in the buyer's institutional choice that was highlighted above. If $C^{\text {entry }}$ is such that the buyer prefers an auction to multilateral negotiations for a certain number of invited sellers, the buyer might still prefer multilateral negotiations after suitably reducing the number of invited sellers.

Figure 5 illustrates the buyer's expected payoff when it optimally chooses how many sellers to invite, restricting attention to a setting in which there are $N=10$ sellers available. Each panel reflects a different ratio of the discount rates, $\frac{r_{B}}{r_{S}}$. Each line in Figure 5 is the upper envelope from plotting the buyer's expected payoff for each number of invited sellers for a particular institution, such as the three reported in Figure 4.

\section{Figure 5 Here}

The first insight from Figure 5 is that, even optimizing over the number of invited sellers, the buyer prefers multilateral negotiations for sufficiently low values of $C^{\text {entry }}$, and prefers a first-price auction for sufficiently high values of $C^{\text {entry }}$. For very low values of $C^{\text {entry }}$, all invited sellers participate even if all sellers are invited. In this case the buyer invites all sellers and prefers multilateral negotiations, as shown in Proposition 2. For values of $C^{e n t r y} \in\left(\pi_{S}^{m l n}(1), \pi_{S}^{f p a}(1)\right)$, no sellers participate in multilateral negotiations, but participate with positive probability in a first-price auction. Consequently, for such values of $C^{e n t r y}$ the buyer prefers a first-price auction to multilateral negotiations.

The second insight from Figure 5 is that the specifics of the buyer's institutional choice are murky for intermediate values of $C^{\text {entry }}$. While there obviously is a change at some point from preferring multilateral negotiations to preferring an auction, there can be multiple such changes as $C^{\text {entry }}$ increases. For example, in panel (b) the buyer's optimal choice is to invite 2 sellers and use multilateral negotiations when $C^{\text {entry }}=0.14$, to invite 2 sellers and use a first-price auction when $C^{\text {entry }}=0.17$, and to invite 1 seller and use multilateral negotiations when $C^{\text {entry }}=0.23$. Once $C^{\text {entry }}>0.25$ the buyer switches back to inviting 2 sellers and using a first-price auction.

Finally, one could assess how the effects of costly entry are influenced by the variance of the $V_{i}$ draws. An informal analysis similar to that in Subsection 4.2 suggests that the two institutions are equivalent if the variance of the $V_{i}$ draws is sufficiently low. Hence, entry costs would not affect the buyer's institutional choice.

\section{Conclusions and Future Research}

This paper develops a model of multilateral negotiations with complete information by adding additional sellers to Rubinstein's classic infinite-horizon alternating-offers model of bilateral negotiations. The model's unique stationary SPNE outcomes involve the buyer trading immediately with the surplus-maximizing seller. 
The presence of additional sellers in certain instances provides a measure of protection to the buyer that enables it to receive higher payoffs than it otherwise would. In other instances the additional sellers are irrelevant, because the surplus available from trading with them is too low to give the buyer a credible threat to trade with them if seller 1 is intransigent. In the limit as the time between offers goes to 0 , these stationary outcomes have an intuitively appealing structure that is consonant with the SPNE outcome from bilateral negotiations: The prospect of trade with seller 2 constrains the multilateral negotiations if and only if $V_{2}$ exceeds what the buyer would obtain in bilateral negotiations with seller 1 .

I apply the model to the buyer's choice between conducting procurement via multilateral negotiations or an auction. As a general matter the buyer tends to prefer multilateral negotiations when the buyer is relatively patient, when the sellers' products are distinct or their production costs are quite different, and when there are few sellers. In such settings the buyer's bargaining ability plays a significant role in the negotiations, and the buyer forgoes that ability by conducting procurement with an auction. However, the buyer prefers an auction if it is sufficiently costly for sellers to participate in the procurement process, because sellers' anticipated low payoffs in multilateral negotiations make them less likely to participate than if procurement were conducted with an auction. These differences in the buyer's institutional preference are maintained if the buyer can strategically limit the number of sellers it invites to participate, and a new one emerges: For intermediate entry costs the buyer can prefer either institution, and the preferred choice can change multiple times as the entry cost increases.

The analysis of the buyer's choice helps explain why multilateral negotiations and auctions are used by apparently similar buyers. In some instances the two institutions might coexist because each gives the buyer the same expected payoff, such as when there is little variation in the surpluses available from different sellers. In other instances buyers might have distinct preferences that depend on factors including variation in the cost of sellers' participation across buyers (say because of complexity in determining a seller's fit with the buyer's preferences), differences in the buyers' bargaining ability relative to the sellers', or differences in the buyers' costs of conducting multilateral negotiations.

The model illustrates a setting in which multilateral negotiations can be evaluated straightforwardly, and the following examples give a sense of the variety of ways in which it can be applied. One could use the model to evaluate horizontal mergers in markets where the strategic interaction among firms involves multilateral negotiations. The basic model is sufficiently simple that one could include merger-specific efficiencies or changes in bargaining positions, changes in product offerings from the merging firms or their rivals, or entry by new sellers. Likewise, one could consider collusion amongst sellers who repeatedly compete for the business of buyers. The model's emphasis on surplus allows consideration of cost differences across sellers, or of horizontal and vertical product differentiation. One also could consider incentives regarding dual-sourcing, sellers' investments to reduce costs or improve their products' goodness-of-fit with the buyer's preferences, the buyer's design of its purchasing requirements, or joint decisions between the buyer and each seller on relationship-specific investments. Finally, one could use the model as a starting point for designing experiments. In addition to comparing experimental outcomes to the model's predictions regarding parameters such as the available surpluses, the parties' discount rates, or the number of sellers, one also can assess whether a structured model of multilateral negotiations can reasonably explain the outcomes of more realistic unstructured negotiations. 


\section{Appendix}

This appendix contains proofs of Theorem 1, Corollary 1, and Propositions 1 and 2. It begins with several lemmas that are used in the proof of Theorem 1.

I will frequently refer to SPNE strategies by $\sigma \equiv\left\{\sigma_{B}, \sigma_{1}, \sigma_{2}, \ldots, \sigma_{N}\right\}$, where $\sigma_{k}$ denotes player $k$ 's strategy in the infinite-horizon game, for $k \in\{B, 1, \ldots, N\}$. Let $\pi_{k}^{s o}$ and $\pi_{k}^{b o}$ respectively denote player $k$ 's stationary SPNE payoffs in subgames that begin with offers from the sellers and from the buyer, for some SPNE $\sigma$.

Lemma 1 In subgames beginning with offers from the sellers, all SPNE featuring stationary outcomes involve trade between the buyer and seller 1 in the subgame's initial period.

Proof of Lemma 1: In an arbitrary subgame beginning with offers from the sellers, consider a SPNE $\sigma$ that supports the stationary payoffs $\pi_{k}^{s o}$ and $\pi_{k}^{b o}$. Note that $\pi_{B}^{s o} \geq \delta_{B} \pi_{B}^{b o}$, because the buyer always can let play continue to the next period by rejecting all offers in the subgame's initial period.

I first show that $\sigma$ involves trade between the buyer and seller 1. The proof involves three cases.

Case 1: Suppose $\sigma$ involves trade between the buyer and a seller $k \neq 1$ for which $V_{k}=V_{1}$. Relabel the sellers so that trade involves seller 1 .

Case 2: Suppose $\sigma$ involves trade between the buyer and a seller $k$ for which $V_{k}<V_{1}$. By following $\sigma$, $\pi_{B}^{s o} \leq V_{k}<V_{1}$ and $\pi_{1}^{s o}=0$.

In the subgame's initial period, I can show that seller 1 can profitably deviate from $\sigma$ by offering the buyer $V_{1}-\epsilon>\pi_{B}^{s o}$ for some $\epsilon>0$. First, the buyer strictly prefers accepting seller 1's offer, because the payoff $V_{1}-\epsilon$ the buyer receives by accepting strictly exceeds both its payoff from accepting seller $k$ 's offer (which is at most $\pi_{B}^{s o}$, depending on whether $\sigma$ specified a trade in the subgame's initial period), and its payoff from rejecting all offers and letting play continue to the next period (which is $\delta_{B} \pi_{B}^{b o} \leq \pi_{B}^{s o}$ ). Second, seller 1 strictly prefers offering $V_{1}-\epsilon$, because the payoff $\epsilon$ seller 1 receives by doing strictly exceeds its payoff from following $\sigma$ (which is 0 ). The existence of this profitable deviation implies $\sigma$ cannot involve the buyer trading with a seller $k$ for which $V_{k}<V_{1}$.

Case 3: Suppose $\sigma$ involves no trade in any period. By following $\sigma, \pi_{B}^{s o}=\pi_{1}^{s o}=\pi_{B}^{b o}=\pi_{1}^{b o}=0$. In the subgame's initial period, I can show that seller 1 can profitably deviate from $\sigma$ by offering the buyer $V_{1}-\epsilon>0$ for some $\epsilon>0$. First, the buyer strictly prefers accepting seller 1's offer, because the payoff $V_{1}-\epsilon$ the buyer receives by accepting strictly exceeds both its payoff from accepting any other seller's offer, and its payoff from rejecting all offers and letting play continue to the next period (both of which must be 0 , else the buyer's payoff could not be 0 according to $\sigma$ ). Second, seller 1 strictly prefers offering $V_{1}-\epsilon$, because the payoff $\epsilon$ seller 1 receives by doing so strictly exceeds its payoff from following $\sigma$ (which is 0 ). The existence of this profitable deviation implies $\sigma$ cannot involve no trade in any period.

Cases 1-3 exhaust all possibilities other than trading with seller 1, and so in all subgames beginning with offers from the sellers, all SPNE featuring stationary outcomes involve trade with seller 1.

I next show that $\sigma$ involves trade in the subgame's initial period. Suppose not. Because of discounting, this delay in trading implies $\pi_{1}^{s o}+\pi_{B}^{s o}<V_{1}$. In the subgame's initial period, I can show that seller 1 can profitably deviate from $\sigma$ by offering the buyer $\pi_{B}^{s o}+\epsilon$ for some $\epsilon>0$ such that $\pi_{1}^{s o}+\pi_{B}^{s o}+\epsilon<V_{1}$. First, the buyer strictly prefers accepting seller 1's offer, because the payoff $\pi_{B}^{s o}+\epsilon$ the buyer receives by accepting strictly exceeds both its payoff from accepting any other seller's offer (which is at most $\pi_{B}^{s o}$ ), and its payoff from rejecting all offers and letting play continue to the next period (which is $\delta_{B} \pi_{B}^{b o} \leq \pi_{B}^{s o}$ ). Second, seller 1 strictly prefers offering $\pi_{B}^{s o}+\epsilon$, because the payoff $V_{1}-\left(\pi_{B}^{s o}+\epsilon\right)$ seller 1 receives by doing so strictly exceeds 
its payoff from following $\sigma$ (which is $\pi_{1}^{s o}<V_{1}-\left(\pi_{B}^{s o}+\epsilon\right)$ ). The existence of this profitable deviation implies $\sigma$ cannot involve trade not occurring in the subgame's initial period.

Lemma 2 In subgames beginning with offers from the buyer, all SPNE featuring stationary outcomes involve trade between the buyer and seller 1 in the subgame's initial period.

Proof of Lemma 2: In an arbitrary subgame beginning with offers from the buyer, consider a SPNE $\sigma$ that supports the stationary payoffs $\pi_{k}^{b o}$ and $\pi_{k}^{s o}$. Note that $\pi_{B}^{b o} \geq \delta_{B} \pi_{B}^{s o}$, because the buyer always can let play continue to the next period by refusing to trade with any seller who accepted the buyer's proposal in the subgame's initial period.

I first show that $\sigma$ involves trade between the buyer and seller 1 . The proof involves three cases.

Case 1: Suppose $\sigma$ involves trade between the buyer and a seller $k \neq 1$ for which $V_{k}=V_{1}$. Relabel the sellers so that trade involves seller 1.

Case 2: Suppose $\sigma$ involves trade between the buyer and a seller $k$ for which $V_{k}<V_{1}$. Trade must occur in the subgame's initial period, because by Lemma 1 trade involves the buyer and seller 1 if play continues to the subgame's next period. By following $\sigma, \pi_{B}^{b o} \leq V_{k}<V_{1}$, and $\pi_{1}^{b o}=0$.

If $\pi_{B}^{b o}>\delta_{B} \pi_{B}^{s o}$, then in the subgame's initial period I can show that the buyer can profitably deviate from $\sigma$ by offering $V_{j}$ to each seller $j \neq 1, k$, and offering $\epsilon>0$ to sellers 1 and $k$ such that $V_{1}-\epsilon>V_{k}-\epsilon \geq$ $\pi_{B}^{b o}-\epsilon>\delta_{B} \pi_{B}^{s o}$, and $V_{1}-\epsilon>\pi_{B}^{b o}$. First consider the buyer's decision to trade after the sellers make their accept/reject decisions. If seller $k$ accepts and seller 1 rejects, then the buyer strictly prefers trading with seller $k$ because the payoff $V_{k}-\epsilon$ the buyer receives by doing so strictly exceeds both its payoff from trading with any other seller $j \neq 1, k$ (which is 0 ), and its payoff from letting play continue to the next period (which is $\delta_{B} \pi_{B}^{s o}$ ). If seller 1 accepts, then the buyer strictly prefers trading with seller 1 because the payoff $V_{1}-\epsilon$ the buyer receives by doing so strictly exceeds both its payoff from trading with any other seller (which is at most $V_{k}-\epsilon$ ), and its payoff from letting play continue to the next period (which is $\delta_{B} \pi_{B}^{s o}$ ). Next consider the sellers' accept/reject decisions after receiving the deviating offers. In any equilibrium seller $k$ accepts if seller 1 rejects, because seller $k$ anticipates trading with the buyer and receiving a payoff $\epsilon$ that strictly exceeds its payoff from rejecting (which is 0 ). Consequently, in any equilibrium seller 1 must accept the buyer's deviating offer, because it anticipates trading with the buyer and receiving a payoff $\epsilon$ that strictly exceeds its payoff from rejecting (which is 0). Finally, making the specified deviating offers gives the buyer a strictly higher payoff than from following $\sigma$. The existence of this profitable deviation implies $\sigma$ cannot involve the buyer trading with a seller $k$ for which $V_{k}<V_{1}$.

If $\pi_{B}^{b o}=\delta_{B} \pi_{B}^{s o}$, then in the subgame's initial period I can show that the buyer can profitably deviate from $\sigma$ by offering $V_{j}$ to each seller $j \neq 1$, and offering $\delta_{1}\left(V_{1}-\pi_{B}^{s o}\right)+\epsilon\left\langle V_{1}\right.$ to seller 1 for some $\epsilon>0$. First consider the buyer's decision to trade after the sellers make their accept/reject decisions. If seller 1 accepts, then the buyer strictly prefers trading with seller 1 because the payoff $V_{1}-\delta_{1}\left(V_{1}-\pi_{B}^{s o}\right)-\epsilon$ the buyer receives by doing strictly exceeds its payoff from trading with any other seller (which is 0 ), and its payoff from letting play continue to the next period. To see the latter point, by trading with seller 1 the buyer's payoff can be written as $\left(1-\delta_{1}\right) V_{1}+\delta_{1} \pi_{B}^{s o}-\epsilon$. There are three cases to consider.

- If $\pi_{B}^{s o}=V_{1}$, then by trading in the current period the buyer's payoff is $V_{1}-\epsilon>\delta_{B} V_{1}=\pi_{B}^{b o}$ for sufficiently small $\epsilon>0$. Thus, the buyer prefers trading in the current period.

- If $0<\pi_{B}^{s o}<V_{1}$, then by trading in the current period the buyer's payoff strictly exceeds $\pi_{B}^{s o}-\epsilon=$ $\frac{\pi_{B}^{b o}}{\delta_{B}}-\epsilon>\pi_{B}^{b o}$, for sufficiently small $\epsilon>0$. Thus, the buyer prefers trading in the current period. 
- If $0=\pi_{B}^{s o}$, then $\pi_{B}^{b o}=0$, and by trading in the current period the buyer's payoff is $\left(1-\delta_{1}\right) V_{1}-\epsilon>0$ $\left(=\pi_{B}^{b o}\right)$ for sufficiently small $\epsilon>0$. Thus, the buyer prefers trading in the current period.

Next consider the sellers' accept/reject decisions. If the buyer offers seller $1 \delta_{1}\left(V_{1}-\pi_{B}^{s o}\right)+\epsilon$, then seller 1 strictly prefers accepting. By accepting seller 1 anticipates trading with the buyer this period and getting a payoff of $\delta_{1}\left(V_{1}-\pi_{B}^{s o}\right)+\epsilon$, while by rejecting seller 1 expects at best a strictly lower payoff $\delta_{1}\left(V_{1}-\pi_{B}^{s o}\right)$. Therefore, making the specified offers gives the buyer a strictly higher payoff than from following $\sigma$. The existence of this profitable deviation implies $\sigma$ cannot involve the buyer trading with a seller $k$ for which $V_{k}<V_{1}$.

Case 3: Suppose $\sigma$ involves no trade in any period. Once play reaches the subgame's second period (in which sellers make offers to the buyer), by Lemma 1 trade will occur, which is a contradiction.

Cases 1-3 exhaust all possibilities other than trading with seller 1, and so in all subgames beginning with offers from the buyer, all SPNE featuring stationary outcomes involve trade with seller 1.

I next show that $\sigma$ involves trade in the subgame's initial period. Suppose not. Because of discounting, this delay in trading implies $\pi_{1}^{b o}+\pi_{B}^{b o}<V_{1}$. In the subgame's initial period, I can show that the buyer can profitably deviate from $\sigma$ by offering seller $1 \pi_{1}^{b o}+\epsilon$ for some $\epsilon>0$ such that $\pi_{1}^{b o}+\pi_{B}^{b o}+\epsilon<V_{1}$, while making offers to the remaining sellers according to $\sigma$. First, the buyer strictly prefers trading with seller 1 if seller 1 accepts this offer, because the buyer's payoff $V_{1}-\left(\pi_{1}^{b o}+\epsilon\right)$ from doing so strictly exceeds its payoff from trading with any other seller (which is at most $\pi_{B}^{b o}$ ), and its payoff from rejecting all offers and letting play continue to the next period (which is $\delta_{B} \pi_{B}^{s o} \leq \pi_{B}^{b o}$ ). Second, seller 1 strictly prefers accepting the buyer's offer, because its payoff $\pi_{1}^{b o}+\epsilon$ from doing so strictly exceeds its payoff from rejecting the offer (which is at most $\pi_{1}^{b o}$ ). Therefore, the buyer strictly prefers offering $\pi_{1}^{b o}+\epsilon$ to seller 1 , because doing so gives the buyer a strictly higher payoff than from following $\sigma$. The existence of this profitable deviation implies $\sigma$ cannot involve trade not occurring in the subgame's initial period.

Lemma 3 In all stationary SPNE outcomes, $\pi_{1}^{s o}=V_{1}-\max \left[V_{2}, \delta_{B} \pi_{B}^{b o}\right]$.

Proof of Lemma 3: In an arbitrary subgame beginning with offers from the sellers, consider a SPNE $\sigma$ that supports the stationary payoffs $\pi_{k}^{s o}$ and $\pi_{k}^{b o}$.

Suppose $\pi_{1}^{s o}<V_{1}-\max \left[V_{2}, \delta_{B} \pi_{B}^{b o}\right]$. In the subgame's initial period, I can show that seller 1 can profitably deviate from $\sigma$ by demanding $\pi_{1}^{s o}+\epsilon<V_{1}-\max \left[V_{2}, \delta_{B} \pi_{B}^{b o}\right]$, for some $\epsilon>0$. The buyer strictly prefers accepting this demand, because its payoff from doing so is $V_{1}-\left(\pi_{1}^{s o}+\epsilon\right)>\max \left[V_{2}, \delta_{B} \pi_{B}^{b o}\right]$, where $\max \left[V_{2}, \delta_{B} \pi_{B}^{b o}\right]$ is the highest payoff the buyer can get by rejecting seller 1's demand (either at most $V_{2}$ by trading this period with another seller, or $\delta_{B} \pi_{B}^{b o}$ by rejecting all offers and letting play continue to the next period). Given the buyer's anticipated behavior, seller 1's payoff from demanding $\pi_{1}^{s o}+\epsilon$ strictly exceeds its payoff from following $\sigma$ (which is $\pi_{1}^{s o}$ ). The existence of this profitable deviation implies that $\pi_{1}^{s o} \geq V_{1}-\max \left[V_{2}, \delta_{B} \pi_{B}^{b o}\right]$.

Now suppose $\pi_{1}^{s o}>V_{1}-\max \left[V_{2}, \delta_{B} \pi_{B}^{b o}\right]$. In the subgame's initial period, by Lemma 1 the buyer's payoff according to $\sigma$ is $V_{1}-\pi_{1}^{s o}<\max \left[V_{2}, \delta_{B} \pi_{B}^{b o}\right]$. If $\delta_{B} \pi_{B}^{b o} \geq V_{2}$, then the buyer strictly prefers rejecting all offers and letting play continue to the next period, because the buyer's payoff $\delta_{B} \pi_{B}^{b o}$ from doing so strictly exceeds its payoff from following $\sigma$. If $V_{2}>\delta_{B} \pi_{B}^{b o}$, then seller 2 strictly prefers deviating from $\sigma$ by offering $V_{2}-\epsilon>\max \left[V_{1}-\pi_{1}^{s o}, \delta_{B} \pi_{B}^{b o}\right]$, for some $\epsilon>0$. The buyer strictly prefers accepting seller 2's offer, because the buyer's payoff $V_{2}-\epsilon$ from doing so strictly exceeds its payoff both from accepting seller 1's offer (which is $V_{1}-\pi_{1}^{s o}$ ), and its payoff from rejecting all offers and letting play continue to the next period (which is $\delta_{B} \pi_{B}^{b o}$ ). 
Given the buyer's anticipated behavior, seller 2's payoff $\epsilon$ from offering $V_{2}-\epsilon$ strictly exceeds its payoff from following $\sigma$ (which is 0 ). The existence of these profitable deviations implies $\pi_{1}^{s o} \leq V_{1}-\max \left[V_{2}, \delta_{B} \pi_{B}^{b o}\right]$.

The arguments in the two preceding paragraphs imply $\pi_{1}^{s o}=V_{1}-\max \left[V_{2}, \delta_{B} \pi_{B}^{b o}\right]$.

Lemma 4 In all stationary SPNE outcomes, if $V_{2}>\delta_{B}\left(V_{1}-\pi_{1}^{s o}\right)$, then $\pi_{B}^{b o}=V_{1}$.

Proof of Lemma 4: In an arbitrary subgame beginning with offers from the buyer, consider a SPNE $\sigma$ that supports the stationary payoffs $\pi_{k}^{b o}$ and $\pi_{k}^{s o}$, and for which $V_{2}>\delta_{B}\left(V_{1}-\pi_{1}^{s o}\right)$.

Suppose $\pi_{B}^{b o}<V_{1}$. In the subgame's initial period, I can show that the buyer can profitably deviate from $\sigma$ by demanding $V_{1}-\frac{\epsilon}{2}>\pi_{B}^{b o}$ from seller 1 and $V_{2}-\epsilon>\delta_{B}\left(V_{1}-\pi_{1}^{s o}\right)$ from seller 2, for some $\epsilon>0$, and demanding 0 from all other sellers.

First consider the buyer's decision whether to trade with any seller that has accepted the buyer's proposal. If seller 1 accepts the buyer's offer, then the buyer strictly prefers trading this period with seller 1 , because the buyer's payoff $V_{1}-\frac{\epsilon}{2}$ from doing so strictly exceeds the buyer's payoff from trading this period with any other seller (which is at most $V_{2}-\epsilon$ ), and its payoff from letting play continue to the next period (which is $\delta_{B}\left(V_{1}-\pi_{1}^{s o}\right)$ ). If seller 2 accepts the buyer's offer and seller 1 rejects, then the buyer strictly prefers trading this period with seller 2 , because the buyer's payoff $V_{2}-\epsilon$ from doing so strictly exceeds its payoff from trading this period with any other seller (which is 0 ), and its payoff from letting play continue to the next period (which is $\delta_{B}\left(V_{1}-\pi_{1}^{s o}\right)$ ).

Now consider the sellers' decisions to accept or reject the buyer's proposals. If seller 1 rejects the buyer's offer, then seller 2 strictly prefers accepting to rejecting the buyer's offer: the buyer will trade this period with seller 2, as noted in the preceding paragraph. Seller 2's payoff in this case is $\epsilon>0$, which strictly exceeds its payoff from rejecting the buyer's offer (which is 0 ).

Because of seller 2's incentives, if seller 1 rejects the buyer's offer, then seller 1's payoff is 0 . If seller 1 accepts the buyer's offer, then seller 1's payoff is $\frac{\epsilon}{2}>0$. Hence, seller 1 accepts the buyer's offer $\frac{\epsilon}{2}$.

Finally, given the sellers' anticipated behavior the buyer strictly prefers making these deviating offers, because the buyer's payoff $V_{1}-\frac{\epsilon}{2}$ from doing strictly exceeds its payoff from following $\sigma$. The existence of this profitable deviation implies that it cannot be that $\pi_{B}^{b o}<V_{1}$, according to $\sigma$, so it must be the case that $\pi_{B}^{b o}=V_{1}$.

Lemma 5 In all stationary SPNE outcomes, if $V_{2}<\delta_{B}\left(V_{1}-\pi_{1}^{s o}\right)$, then $\pi_{B}^{b o}=V_{1}-\delta_{1} \pi_{1}^{s o}$.

Proof of Lemma 5: In an arbitrary subgame beginning with offers from the buyer, consider a SPNE $\sigma$ that supports the stationary payoffs $\pi_{k}^{b o}$ and $\pi_{k}^{s o}$, and for which $V_{2}<\delta_{B}\left(V_{1}-\pi_{1}^{s o}\right)$.

Suppose $\pi_{B}^{b o}<V_{1}-\delta_{1} \pi_{1}^{s o}$. In the subgame's initial period, I can show that the buyer can profitably deviate from $\sigma$ by demanding $\pi_{B}^{b o}+\epsilon$ from seller 1 , for some $\epsilon>0$ such that $\pi_{B}^{b o}+\epsilon<V_{1}-\delta_{1} \pi_{1}^{s o}$. First consider the buyer's decision to trade after the sellers make their accept/reject decisions. If seller 1 accepts, then the buyer strictly prefers trading with seller 1 this period, because the buyer's payoff $\pi_{B}^{b o}+\epsilon$ from doing so strictly exceeds its payoff from trading with another seller or letting play continue to next period (both of which are at most $\pi_{B}^{b o}$ ). Next consider the sellers' accept/reject decisions after observing the deviating offer. Seller 1 strictly prefers accepting the offer, because seller 1's payoff $V_{1}-\left(\pi_{B}^{b o}+\epsilon\right)$ from doing so strictly exceeds its payoff from rejecting (which is at most $\delta_{1} \pi_{1}^{s o}$ ). Given seller 1's anticipated behavior, the buyer strictly prefers deviating from $\sigma$ in this fashion, because the buyer's payoff $\pi_{B}^{b o}+\epsilon$ doing so strictly exceeds its payoff from following $\sigma$. The existence of this profitable deviation implies that $\pi_{B}^{b o} \geq V_{1}-\delta_{1} \pi_{1}^{s o}$. 
Now suppose $\pi_{B}^{b o}>V_{1}-\delta_{1} \pi_{1}^{s o}$. By following $\sigma$, according to Lemma 2 trade takes place in the subgame's initial period, which implies seller 1's payoff is $\pi_{1}^{b o}=V_{1}-\pi_{B}^{b o}$. If seller 1 deviates from $\sigma$ by rejecting the buyer's equilibrium offer, and if the buyer does not trade with any other seller in the subgame's initial period, then seller 1's payoff is $\delta_{1} \pi_{1}^{s o}>\pi_{1}^{b o}$. If seller 1 rejects the buyer's offer, then the buyer will not trade with any other seller in the subgame's initial period. The highest payoff the buyer can get is $V_{2}$ by trading with seller 2 , but by waiting until the next period the buyer gets a payoff of $\delta_{B}\left(V_{1}-\pi_{1}^{s o}\right)>V_{2}$. Therefore, it is profitable for seller 1 to reject the buyer's equilibrium offer in the subgame's initial period, which contradicts $\sigma$ as a SPNE. Therefore, it must be the case that $\pi_{B}^{b o} \leq V_{1}-\delta_{1} \pi_{1}^{s o}$.

The arguments in the two preceding paragraphs imply $\pi_{B}^{b o}=V_{1}-\delta_{1} \pi_{1}^{s o}$.

Lemma 6 In all stationary SPNE outcomes, if $V_{2}=\delta_{B}\left(V_{1}-\pi_{1}^{s o}\right)$, then $\pi_{1}^{s o}=V_{1}-\frac{V_{2}}{\delta_{B}}$.

Proof of Lemma 6: Follows from simple algebra.

With the preceding results, the stationary equilibrium payoffs can be derived for each of four cases.

\subsection{Case 1: $V_{2}<\delta_{B}\left(V_{1}-\pi_{1}^{s o}\right)$}

Lemma 7 If $V_{2}<\delta_{B}\left(V_{1}-\pi_{1}^{s o}\right)$, then

$$
\pi_{B}^{b o}=\left(\frac{1-\delta_{1}}{1-\delta_{1} \delta_{B}}\right) V_{1} \quad \pi_{1}^{b o}=\delta_{1}\left(\frac{1-\delta_{B}}{1-\delta_{1} \delta_{B}}\right) V_{1} \quad \pi_{B}^{s o}=\delta_{B}\left(\frac{1-\delta_{1}}{1-\delta_{1} \delta_{B}}\right) V_{1} \quad \pi_{1}^{s o}=\left(\frac{1-\delta_{B}}{1-\delta_{1} \delta_{B}}\right) V_{1} .
$$

Proof of Lemma 7: By Lemma 3, $\pi_{1}^{s o}=V_{1}-\max \left[V_{2}, \delta_{B} \pi_{B}^{b o}\right]$. Substituting the expression for $\pi_{1}^{s o}$ into the condition for Lemma 7 requires $V_{2}<\delta_{B} \max \left[V_{2}, \delta_{B} \pi_{B}^{b o}\right]$, so for Lemma 7's condition to hold requires $\delta_{B} \pi_{B}^{b o}=\max \left[V_{2}, \delta_{B} \pi_{B}^{b o}\right]$.

By Lemma $5, \pi_{B}^{b o}=V_{1}-\delta_{1} \pi_{1}^{s o}$. Substituting the expression for $\pi_{1}^{s o}$ into the expression for $\pi_{B}^{b o}$ yields

$$
\pi_{B}^{b o}=V_{1}-\delta_{1}\left(V_{1}-\delta_{B} \pi_{B}^{b o}\right) \Longleftrightarrow \pi_{B}^{b o}=\left(\frac{1-\delta_{1}}{1-\delta_{1} \delta_{B}}\right) V_{1}
$$

Substituting the derived value for $\pi_{B}^{b o}$ into the expression for $\pi_{1}^{s o}$ yields $\pi_{1}^{s o}=\left(\frac{1-\delta_{B}}{1-\delta_{1} \delta_{B}}\right) V_{1}$. By Lemmas 1 and $2, \pi_{1}^{b o}=\delta_{1}\left(\frac{1-\delta_{B}}{1-\delta_{1} \delta_{B}}\right) V_{1}$ and $\pi_{B}^{s o}=\delta_{B}\left(\frac{1-\delta_{1}}{1-\delta_{1} \delta_{B}}\right) V_{1}$. These are the desired results.

Lemma 8 If $V_{2}<\delta_{B}\left(V_{1}-\pi_{1}^{s o}\right)$, then $V_{2}<\delta_{B}^{2}\left(\frac{1-\delta_{1}}{1-\delta_{1} \delta_{B}}\right) V_{1}$.

Proof of Lemma 8: If $V_{2}<\delta_{B}\left(V_{1}-\pi_{1}^{s o}\right)$, then $\pi_{1}^{s o}=\left(\frac{1-\delta_{B}}{1-\delta_{1} \delta_{B}}\right) V_{1}$ by Lemma 7 . Substituting that expression into the condition for Lemma 8 yields $V_{2}<\delta_{B}^{2}\left(\frac{1-\delta_{1}}{1-\delta_{1} \delta_{B}}\right) V_{1}$, which is the desired result.

6.2 Case 2: $V_{2}>\delta_{B}\left(V_{1}-\pi_{1}^{s o}\right)$ and $V_{2} \geq \delta_{B} \pi_{B}^{b o}$

Lemma 9 If $V_{2}>\delta_{B}\left(V_{1}-\pi_{1}^{s o}\right)$ and $V_{2} \geq \delta_{B} \pi_{B}^{b o}$, then

$$
\pi_{B}^{b o}=V_{1} \quad \pi_{1}^{b o}=0 \quad \pi_{B}^{s o}=V_{2} \quad \pi_{1}^{s o}=V_{1}-V_{2}
$$


Proof of Lemma 9: By Lemma 3, $\pi_{1}^{s o}=V_{1}-\max \left[V_{2}, \delta_{B} \pi_{B}^{b o}\right]$, so the second condition for Lemma 9 implies $\pi_{1}^{s o}=V_{1}-V_{2}$. By Lemma $4, \pi_{B}^{b o}=V_{1}$. By Lemmas 1 and $2, \pi_{1}^{b o}=0$ and $\pi_{B}^{s o}=V_{2}$. These are the desired results.

Lemma 10 If $V_{2}>\delta_{B}\left(V_{1}-\pi_{1}^{s o}\right)$ and $V_{2} \geq \delta_{B} \pi_{B}^{b o}$, then $V_{2} \geq \delta_{B} V_{1}$.

Proof of Lemma 10: If $V_{2}>\delta_{B}\left(V_{1}-\pi_{1}^{s o}\right)$ and $V_{2} \geq \delta_{B} \pi_{B}^{b o}$, then substituting the stationary SPNE payoffs derived in Lemma 9 into the conditions for Lemma 10 yields $V_{2}>\delta_{B} V_{2}$ and $V_{2} \geq \delta_{B} V_{1}$. The first constraint holds trivially, so the relevant constraint is the second one. This is the desired result.

\subsection{Case 3: $V_{2}>\delta_{B}\left(V_{1}-\pi_{1}^{s o}\right)$ and $V_{2}<\delta_{B} \pi_{B}^{b o}$}

Lemma 11 If $V_{2}>\delta_{B}\left(V_{1}-\pi_{1}^{s o}\right)$ and $V_{2}<\delta_{B} \pi_{B}^{b o}$, then

$$
\pi_{B}^{b o}=V_{1} \quad \pi_{1}^{b o}=0 \quad \pi_{B}^{s o}=\delta_{B} V_{1} \quad \pi_{1}^{s o}=\left(1-\delta_{B}\right) V_{1}
$$

Proof of Lemma 11: By Lemma $4, \pi_{B}^{b o}=V_{1}$. By Lemma $3, \pi_{1}^{s o}=V_{1}-\max \left[V_{2}, \delta_{B} \pi_{B}^{b o}\right]$, so the second condition for Lemma 11 implies $\pi_{1}^{s o}=\left(1-\delta_{B}\right) V_{1}$. By Lemmas 1 and $2, \pi_{1}^{b o}=0$ and $\pi_{B}^{s o}=\delta_{B} V_{1}$. These are the desired results.

Lemma 12 If $V_{2}>\delta_{B}\left(V_{1}-\pi_{1}^{s o}\right)$ and $V_{2}<\delta_{B} \pi_{B}^{b o}$, then $\delta_{B}^{2} V_{1}<V_{2}<\delta_{B} V_{1}$.

Proof of Lemma 12: If $V_{2}>\delta_{B}\left(V_{1}-\pi_{1}^{s o}\right)$ and $V_{2}<\delta_{B} \pi_{B}^{b o}$, then substituting the stationary SPNE payoffs derived in Lemma 11 into the conditions for Lemma 12 yields $V_{2}>\delta_{B}^{2} V_{1}$ and $V_{2}<\delta_{B} V_{1}$. These are the desired results.

\subsection{Case 4: $V_{2}=\delta_{B}\left(V_{1}-\pi_{1}^{s o}\right)$}

Lemma 13 If $V_{2}=\delta_{B}\left(V_{1}-\pi_{1}^{s o}\right)$, then

$$
\pi_{B}^{b o}=\frac{V_{2}}{\delta_{B}^{2}} \quad \pi_{1}^{b o}=V_{1}-\frac{V_{2}}{\delta_{B}^{2}} \quad \pi_{B}^{s o}=\frac{V_{2}}{\delta_{B}} \quad \pi_{1}^{s o}=V_{1}-\frac{V_{2}}{\delta_{B}} .
$$

Proof of Lemma 13: By Lemma 6, $\pi_{1}^{s o}=V_{1}-\frac{V_{2}}{\delta_{B}}$. By Lemma $3, \pi_{1}^{s o}=V_{1}-\max \left[V_{2}, \delta_{B} \pi_{B}^{b o}\right]$, so substituting the value of $\pi_{1}^{s o}$ derived in Lemma 6 yields $\frac{V_{2}}{\delta_{B}}=\max \left[V_{2}, \delta_{B} \pi_{B}^{b o}\right]$. Given that $\delta_{B}<1$, it must be that $\delta_{B} \pi_{B}^{b o}=\max \left[V_{2}, \delta_{B} \pi_{B}^{b o}\right]$. Therefore, $\pi_{B}^{b o}=\frac{V_{2}}{\delta_{B}^{2}}$. By Lemmas 1 and $2, \pi_{1}^{b o}=V_{1}-\frac{V_{2}}{\delta_{B}^{2}}$ and $\pi_{B}^{s o}=\frac{V_{2}}{\delta_{B}}$. These are the desired results.

Lemma 14 If $V_{2}=\delta_{B}\left(V_{1}-\pi_{1}^{s o}\right)$, then $\delta_{B}^{2}\left(\frac{1-\delta_{1}}{1-\delta_{1} \delta_{B}}\right) V_{1} \leq V_{2} \leq \delta_{B}^{2} V_{1}$.

Proof of Lemma 14: If $V_{2}=\delta_{B}\left(V_{1}-\pi_{1}^{s o}\right)$, then the stationary SPNE payoffs derived in Lemma 13 are $\pi_{1}^{s o}=V_{1}-\frac{V_{2}}{\delta_{B}}$ and $\pi_{B}^{b o}=\frac{V_{2}}{\delta_{B}^{2}}$. From the first expression, the restriction that $\pi_{1}^{s o} \geq 0$ implies that the proposed solution's validity requires $V_{2} \leq \delta_{B} V_{1}$. From the second expression, the restriction that $\pi_{B}^{b o} \leq V_{1}$ implies that the proposed solution's validity requires $V_{2} \leq \delta_{B}^{2} V_{1}$. The second constraint is tighter than is the first, so the second constraint is the relevant of the two constraints. 
Another restriction is that $\pi_{1}^{b o} \leq \delta_{1} \pi_{1}^{s o}$. If not, then the buyer would be offering seller 1 strictly more than necessary to induce seller 1 to accept the buyer's offer. Given the values of the stationary SPNE payoffs derived in Lemma 13, the proposed solution's validity requires

$$
V_{1}-\frac{V_{2}}{\delta_{B}^{2}} \leq \delta_{1}\left(V_{1}-\frac{V_{2}}{\delta_{B}}\right) \Longleftrightarrow \delta_{B}^{2}\left(\frac{1-\delta_{1}}{1-\delta_{1} \delta_{B}}\right) V_{1} \leq V_{2}
$$

Combining the two parameter restrictions implies that the proposed solution's validity requires $\delta_{B}^{2}\left(\frac{1-\delta_{1}}{1-\delta_{1} \delta_{B}}\right) V_{1} \leq$ $V_{2} \leq \delta_{B}^{2} V_{1}$, which is the desired result.

The preceding Lemmas now can be used to prove Theorem 1.

Proof of Theorem 1: The proof separately considers four sets of possible values for $V_{2}$.

If $V_{2} \in\left[0, \delta_{B}^{2}\left(\frac{1-\delta_{1}}{1-\delta_{1} \delta_{B}}\right) V_{1}\right)$, then $V_{2} \notin\left[\delta_{B}^{2}\left(\frac{1-\delta_{1}}{1-\delta_{1} \delta_{B}}\right) V_{1}, V_{1}\right]$. The contrapositives of Lemmas 10 and 12 imply it is not the case that $V_{2}>\delta_{B}\left(V_{1}-\pi_{1}^{s o}\right)$, while the contrapositive of Lemma 14 implies that it is not the case that $V_{2}=\delta_{B}\left(V_{1}-\pi_{1}^{s o}\right)$. Hence, it must be the case that $V_{2}<\delta_{B}\left(V_{1}-\pi_{1}^{s o}\right)$. Therefore, by Lemma 7 the payoffs must be as specified in Theorem 1 .

If $V_{2} \in\left[\delta_{B}^{2}\left(\frac{1-\delta_{1}}{1-\delta_{1} \delta_{B}}\right) V_{1}, \delta_{B}^{2} V_{1}\right]$, then $V_{2} \notin\left[0, \delta_{B}^{2}\left(\frac{1-\delta_{1}}{1-\delta_{1} \delta_{B}}\right) V_{1}\right)$ and $V_{2} \notin\left(\delta_{B}^{2} V_{1}, V_{1}\right]$. The contrapositive of Lemma 8 implies that it is not the case that $V_{2}<\delta_{B}\left(V_{1}-\pi_{1}^{s o}\right)$, while the contrapositives of Lemmas 10 and 12 imply it is not the case that $V_{2}>\delta_{B}\left(V_{1}-\pi_{1}^{s o}\right)$. Hence, it must be the case that $V_{2}=\delta_{B}\left(V_{1}-\pi_{1}^{s o}\right)$. Therefore, by Lemma 13 the payoffs must be as specified in Theorem 1.

If $V_{2} \in\left(\delta_{B}^{2} V_{1}, \delta_{B} V_{1}\right)$, then $V_{2} \notin\left[0, \delta_{B}^{2}\left(\frac{1-\delta_{1}}{1-\delta_{1} \delta_{B}}\right) V_{1}\right), V_{2} \notin\left[\delta_{B}^{2}\left(\frac{1-\delta_{1}}{1-\delta_{1} \delta_{B}}\right) V_{1}, \delta_{B}^{2} V_{1}\right]$, and $V_{2} \notin\left[\delta_{B} V_{1}, V_{1}\right]$. The contrapositive of Lemma 8 implies that it is not the case that $V_{2}<\delta_{B}\left(V_{1}-\pi_{1}^{s o}\right)$, the contrapositive of Lemma 14 implies that it is not the case that $V_{2}=\delta_{B}\left(V_{1}-\pi_{1}^{s o}\right)$, while the contrapositive of Lemma 10 implies that it is not the case that both $V_{2}>\delta_{B}\left(V_{1}-\pi_{1}^{s o}\right)$ and $V_{2} \geq \delta_{B} \pi_{B}^{b o}$ hold. Hence, it must be the case that $V_{2}>\delta_{B}\left(V_{1}-\pi_{1}^{s o}\right)$ and $V_{2}<\delta_{B} \pi_{B}^{b o}$. Therefore, by Lemma 11 the payoffs must be as specified in Theorem 1.

If $V_{2} \in\left[\delta_{B} V_{1}, V_{1}\right]$, then $V_{2} \notin\left[0, \delta_{B} V_{1}\right)$. The contrapositive of Lemma 8 implies that it is not the case that $V_{2}<\delta_{B}\left(V_{1}-\pi_{1}^{s o}\right)$, the contrapositive of Lemma 14 implies that it is not the case that $V_{2}=\delta_{B}\left(V_{1}-\pi_{1}^{s o}\right)$, while the contrapositive of Lemma 12 implies that it is not the case that both $V_{2}>\delta_{B}\left(V_{1}-\pi_{1}^{s o}\right)$ and $V_{2}<\delta_{B} \pi_{B}^{b o}$ hold. Hence, it must be the case that $V_{2}>\delta_{B}\left(V_{1}-\pi_{1}^{s o}\right)$ and $V_{2} \geq \delta_{B} \pi_{B}^{b o}$. Therefore, by Lemma 9 the payoffs must be as specified in Theorem 1 .

Proof of Corollary 1: Recalling that the discount factor $\delta_{k}$ is defined as $\delta_{k} \equiv e^{-r_{k} \Delta}$, the buyer's payoffs from Theorem 1 can be written as

$$
\begin{array}{ll}
\pi_{B}^{b o}=\left(\frac{1-e^{-r_{1} \Delta}}{1-e^{-r_{1} \Delta} e^{-r_{B} \Delta}}\right) V_{1} & \text { if } V_{2} \in\left[0, e^{-2 r_{B} \Delta}\left(\frac{1-e^{-r_{1} \Delta}}{1-e^{-r_{1} \Delta} e^{-r_{B} \Delta}}\right) V_{1}\right) \\
\pi_{B}^{b o}=\frac{V_{2}}{e^{-2 r_{B} \Delta}} & \text { if } V_{2} \in\left[e^{-2 r_{B} \Delta}\left(\frac{1-e^{-r_{1} \Delta}}{1-e^{-r_{1} \Delta} e^{-r_{B} \Delta}}\right) V_{1}, e^{-2 r_{B} \Delta} V_{1}\right] \\
\pi_{B}^{b o}=V_{1} & \text { if } V_{2} \in\left(e^{-2 r_{B} \Delta} V_{1}, e^{-r_{B} \Delta} V_{1}\right) \\
\pi_{B}^{b o}=V_{1} & \text { if } V_{2} \in\left[e^{-r_{B} \Delta} V_{1}, V_{1}\right]
\end{array}
$$


and

$$
\begin{array}{lll}
\pi_{B}^{s o}=e^{-r_{B} \Delta}\left(\frac{1-e^{-r_{1} \Delta}}{1-e^{-r_{1} \Delta} e^{-r_{B} \Delta}}\right) V_{1} & \text { if } V_{2} \in\left[0, e^{-2 r_{B} \Delta}\left(\frac{1-e^{-r_{1} \Delta}}{1-e^{-r_{1} \Delta} e^{-r_{B} \Delta}}\right) V_{1}\right) \\
\pi_{B}^{s o}=\frac{V_{2}}{e^{-r_{B} \Delta}} & \text { if } V_{2} \in\left[e^{-2 r_{B} \Delta}\left(\frac{1-e^{-r_{1} \Delta}}{1-e^{-r_{1} \Delta} e^{-r_{B} \Delta}}\right) V_{1}, e^{-2 r_{B} \Delta} V_{1}\right] \\
\pi_{B}^{s o}=e^{-r_{B} \Delta} V_{1} & \text { if } V_{2} \in\left(e^{-2 r_{B} \Delta} V_{1}, e^{-r_{B} \Delta} V_{1}\right) \\
\pi_{B}^{s o}=V_{2} & \text { if } V_{2} \in\left[e^{-r_{B} \Delta} V_{1}, V_{1}\right] .
\end{array}
$$

By Lemmas 1 and 2 one can derive the associated values for $\pi_{1}^{b o}$ and $\pi_{1}^{s o}$. Taking the limit as $\Delta \longrightarrow 0$ requires using L'Hopital's rule, which gives the desired result.

\subsection{Proofs of Propositions 1 and 2}

Proof of Proposition 1: The buyer strictly prefers multilateral negotiations if and only if its payoff from multilateral negotiations strictly exceeds its payoff from a first-price auction. That condition amounts to

$$
\pi_{B}^{m l n}>\pi_{B}^{f p a} \Longleftrightarrow \max \left[V_{2},\left(\frac{r_{1}}{r_{1}+r_{B}}\right) V_{1}\right]-C^{m l n}>V_{2}
$$

The latter expression is equivalent to

$$
C^{m l n}<\max \left[0,\left(\frac{r_{1}}{r_{1}+r_{B}}\right) V_{1}-V_{2}\right]
$$

which is the desired result.

The buyer's relative preference for multilateral negotiations intensifies as $\pi_{B}^{m l n}-\pi_{B}^{f p a}$ increases. That condition corresponds to relaxing (1), which is accomplished by decreasing $C^{m l n}$, increasing $V_{1}$, decreasing $V_{2}$, or decreasing $\frac{r_{B}}{r_{1}}$.

Proof of Proposition 2: The buyer strictly prefers multilateral negotiations if and only if its expected payoff from multilateral negotiations strictly exceeds its expected payoff from a first-price auction. That condition amounts to

$$
\pi_{B}^{m l n}>\pi_{B}^{f p a} \Longleftrightarrow \frac{N-1+\left(\frac{r_{S}}{r_{S}+r_{B}}\right)^{N}}{N+1}-C^{m l n}>\frac{N-1}{N+1} .
$$

The latter expression is equivalent to

$$
C^{m l n}<\frac{\left(\frac{r_{S}}{r_{S}+r_{B}}\right)^{N}}{N+1}
$$

which is the desired result.

The buyer's relative preference for multilateral negotiations intensifies as $\pi_{B}^{m l n}-\pi_{B}^{f p a}$ increases. That condition corresponds to relaxing (2), which is accomplished by decreasing $C^{m l n}$, decreasing $N$, or decreasing $\frac{r_{B}}{r_{1}}$.

\section{References}

[1] Ausubel, L., Cramton, P., and Deneckere, R. (2002) "Bargaining with Incomplete Information," in Aumann, R., and Hart, S. (eds.) Handbook of Game Theory 3 (Amsterdam: Elsevier Science B.V.). 
[2] Binmore, K., Shaked, A., and Sutton, J. (1989) "An Outside Option Experiment," Quarterly Journal of Economics, 104, 753-770.

[3] Bulow, J., and Klemperer, P. (1996) "Auctions Versus Negotiations," American Economic Review 86(1), 180-194.

[4] Bulow, J., and Klemperer, P. (2009) "Why Do Sellers (Usually) Prefer Auctions?," American Economic Review 99(4), 1544-1575.

[5] Chamberlin, E. (1948) "An Experimental Imperfect Market," Journal of Political Economy 56, 95-108.

[6] Chatterjee, K., and Dutta, B. (1998) "Rubinstein Auctions: On Competition for Bargaining Partners," Games and Economic Behavior 23(2), 119-145.

[7] Chatterjee, K., and Lee, C. (1998) "Bargaining and Search with Incomplete Information About Outside Options," Games and Economic Behavior 22(2), 203-237.

[8] Dixit, A., and Shapiro, C. (1986) "Entry Dynamics with Mixed Strategies," in Thomas, L.G. (ed.) The Economics of Strategic Planning (Lexington: Lexington Books).

[9] Hendon, E., and Tranaes, T. (1991) "Sequential Bargaining in a Market with One Seller and Two Different Buyers," Games and Economic Behavior 3(4), 453-466.

[10] Kennan, J., and Wilson, R. (1993) "Bargaining with Private Information," Journal of Economic Literature 31, 45-104.

[11] Kim, J., and Che, Y.-K. (2004) "Asymmetric Information About Rivals' Types in Standard Auctions," Games and Economic Behavior 46, 383-397.

[12] Krishna, V., and Serrano, R. (1996) "Multilateral Bargaining," Review of Economic Studies 63(1), 61-80.

[13] Lang, K., and Rosenthal, R. (1991) "The Contractors' Game," RAND Journal of Economics 22(3), 329-338.

[14] Levin, D., and Smith, J. (1994) "Equilibrium in Auctions with Entry," American Economic Review $84(3), 585-599$.

[15] Marx, L., and Shaffer, G. (2010) "Break-up Fees and Bargaining Power in Sequential Contracting," International Journal of Industrial Organization 28, 451-463.

[16] McAdams, D., and Schwarz, M. (2007) "Credible Sales Mechanisms and Intermediaries," American Economic Review 97(1), 260-276.

[17] McAfee, R.P., and McMillan, J. (1987) "Auctions and Bidding," Journal of Economic Literature 25, 699-738.

[18] McAfee, R.P., and Vincent, D. (1997) "Sequentially Optimal Auctions," Games and Economic Behavior 18(2), 246-276.

[19] Milgrom, P. (1989) "Auctions and Bidding: A Primer," Journal of Economic Perspectives 3, 3-22. 
[20] Muthoo, A. (1995) "On the Strategic Role of Outside Options in Bilateral Bargaining," Operations Research 43(2), 292-297.

[21] Muthoo, A. (1999) Bargaining Theory with Applications (Cambridge: Cambridge University Press).

[22] Reinganum, J., and Daughety, A. (1991) "Endogenous Availability in Search Equilibrium," RAND Journal of Economics 22(2), 287-306.

[23] Reinganum, J., and Daughety, A. (1992) "Search Equilibrium with Endogenous Recall," RAND Journal of Economics 23(2), 184-202.

[24] Rubinstein, A. (1982) "Perfect Equilibrium in a Bargaining Model," Econometrica 50(1), 97-109.

[25] Serrano, R. (2008) "Bargaining," in S. Durlauf and L. Blume (eds.) The New Palgrave Dictionary of Economics, $2^{\text {nd }}$ edition (London: McMillan).

[26] Shaked, A. (1994) "Opting Out: Bazaars Versus Hi Tech Markets," Investigaciones Economicas 18(3), 421-432.

[27] Shaked, A., and Sutton, J. (1984) "Involuntary Unemployment as a Perfect Equilibrium in a Bargaining Model," Econometrica 52, 1351-1364.

[28] Smith, V. (1962) "An Experimental Study of Competitive Market Behavior," Journal of Political Economy 70(2), 111-137.

[29] Thomas, C.J. (2011) "Equilibrium Behavior in a Model of Multilateral Negotiations," working paper, Clemson University.

[30] Thomas, C.J., and Wilson, B.J. (2002) "A Comparison of Auctions and Multilateral Negotiations," RAND Journal of Economics 33(1), 140-155.

[31] Thomas, C.J., and Wilson, B.J. (2005) "Verifiable Offers and the Relationship Between Auctions and Multilateral Negotiations," Economic Journal 115(506), 1016-1031.

[32] Thomas, C.J., and Wilson, B.J. (2012) "Horizontal Product Differentiation in Auctions and Multilateral Negotiations," Economica, forthcoming.

[33] Vincent, D. (1992) "Modelling Competitive Behavior," RAND Journal of Economics 23(4), 590-599. 


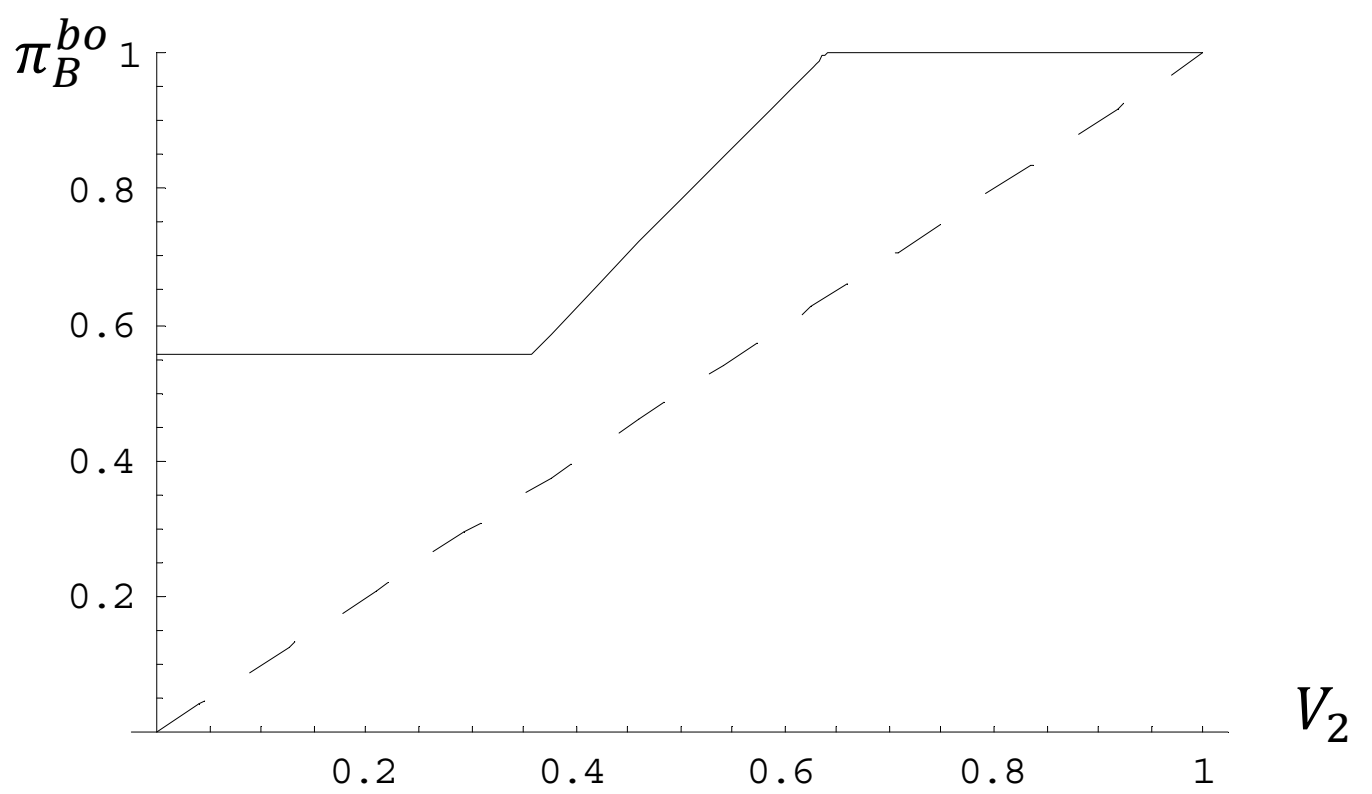

(a) Buyer's stationary SPNE payoffs when buyer makes offers

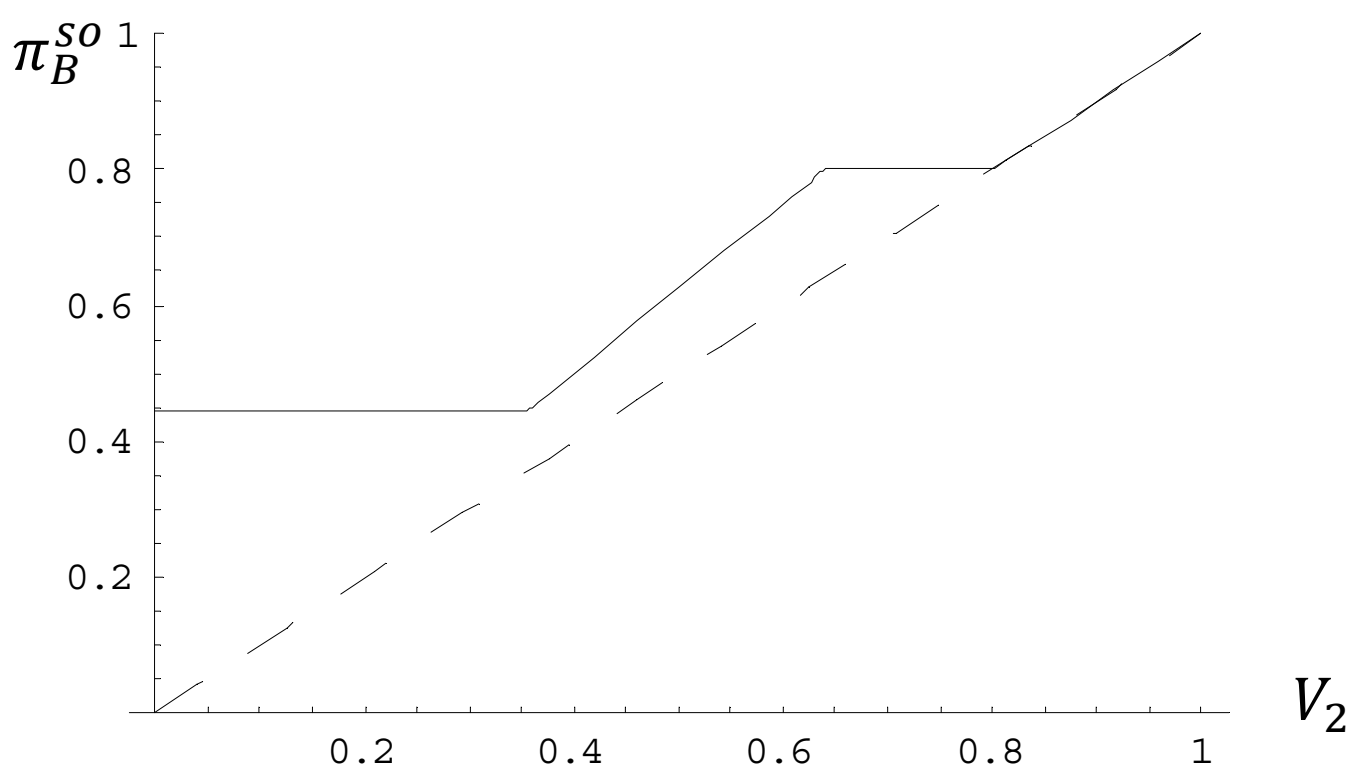

(b) Buyer's stationary SPNE payoffs when sellers make offers

Figure 1. Buyer's Stationary Payoffs in Multilateral Negotiations, as a Function of $\mathbf{V}_{\mathbf{2}}$. Panel (a) shows the buyer's SPNE payoffs as a function of $V_{2}$, in subgames beginning with offers from the buyer. Panel (b) shows the buyer's SPNE payoffs as a function of $\mathrm{V}_{2}$, in subgames beginning with offers from the sellers. These figures are calculated using $\mathrm{V}_{1}=1, \delta_{1}=0.8, \delta_{\mathrm{B}}=0.8$. Dashed line is $45^{\circ}$-line. 


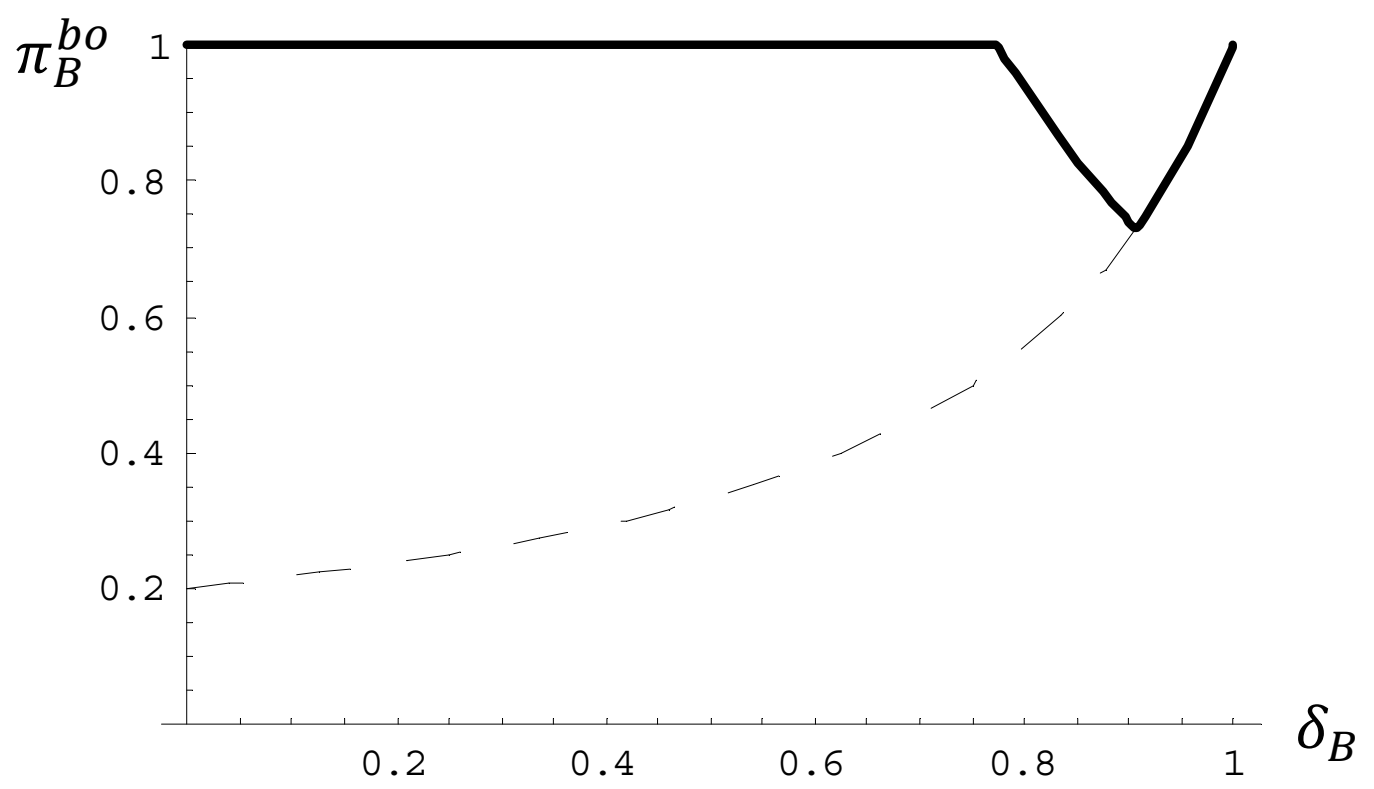

(a) Buyer's stationary SPNE payoffs when buyer makes offers

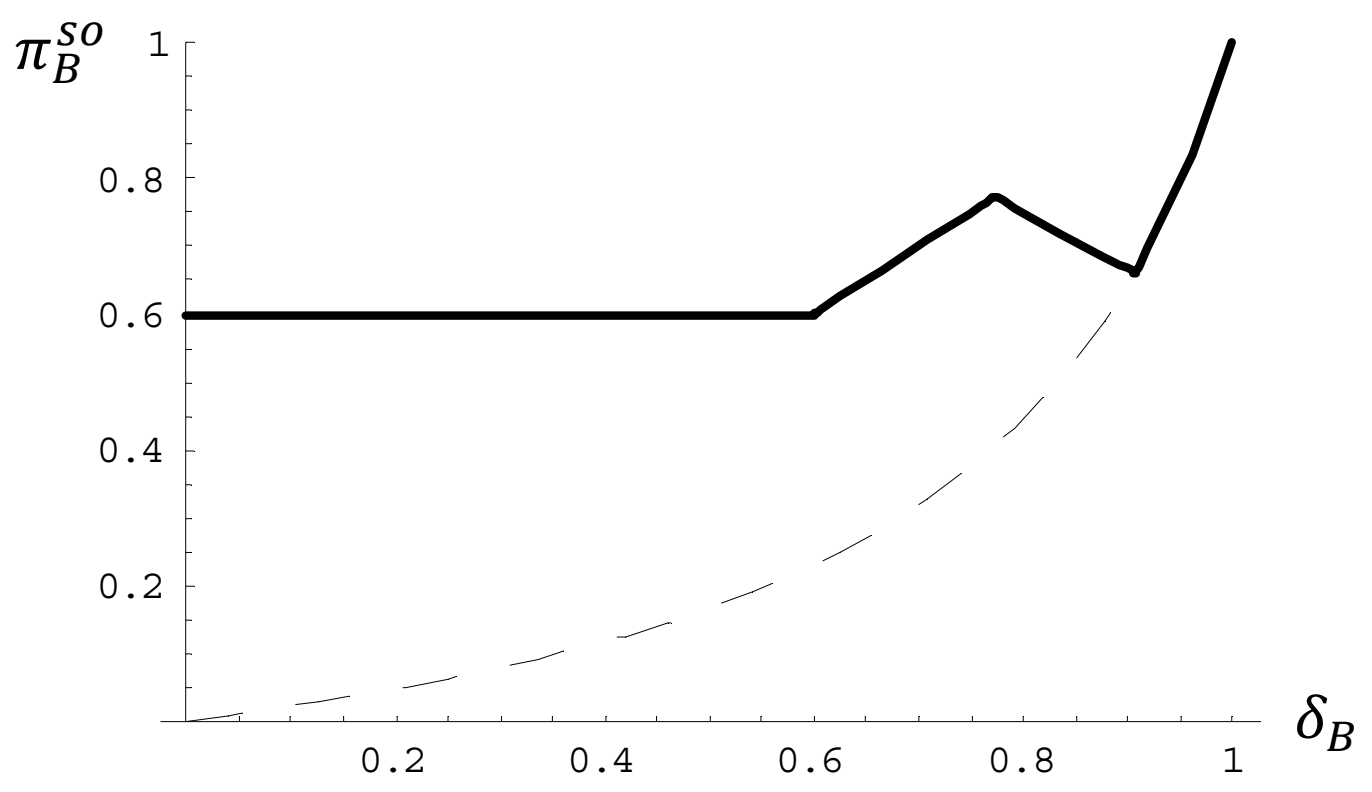

(b) Buyer's stationary SPNE payoffs when sellers make offers

Figure 2. Buyer's Stationary Payoffs in Multilateral Negotiations, as a Function of $\boldsymbol{\delta}_{\mathbf{B}}$. Panel (a) shows the buyer's SPNE payoffs as a function of $\delta_{\mathrm{B}}$, in subgames beginning with offers from the buyer. Panel (b) shows the buyer's SPNE payoffs as a function of $\delta_{\mathrm{B}}$, in subgames beginning with offers from the sellers. These figures are calculated using $\mathrm{V}_{1}=1, \mathrm{~V}_{2}=0.6, \delta_{1}=0.8$. Solid line is stationary SPNE payoff, and dashed line is SPNE payoff from bilateral negotiations. 


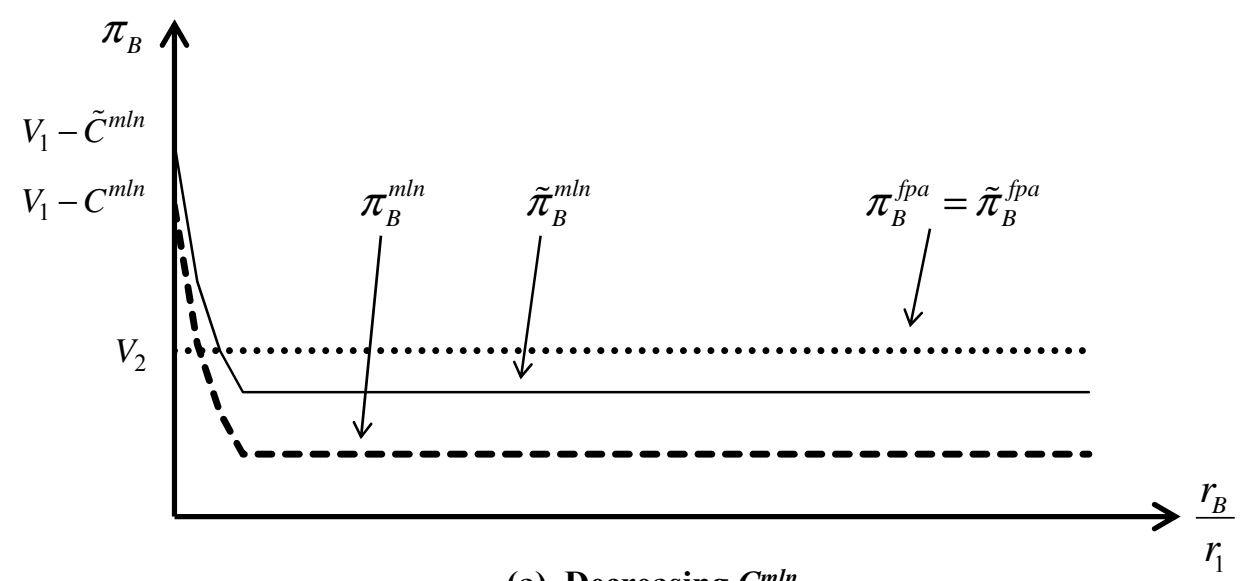

(a) Decreasing $C^{m I n}$
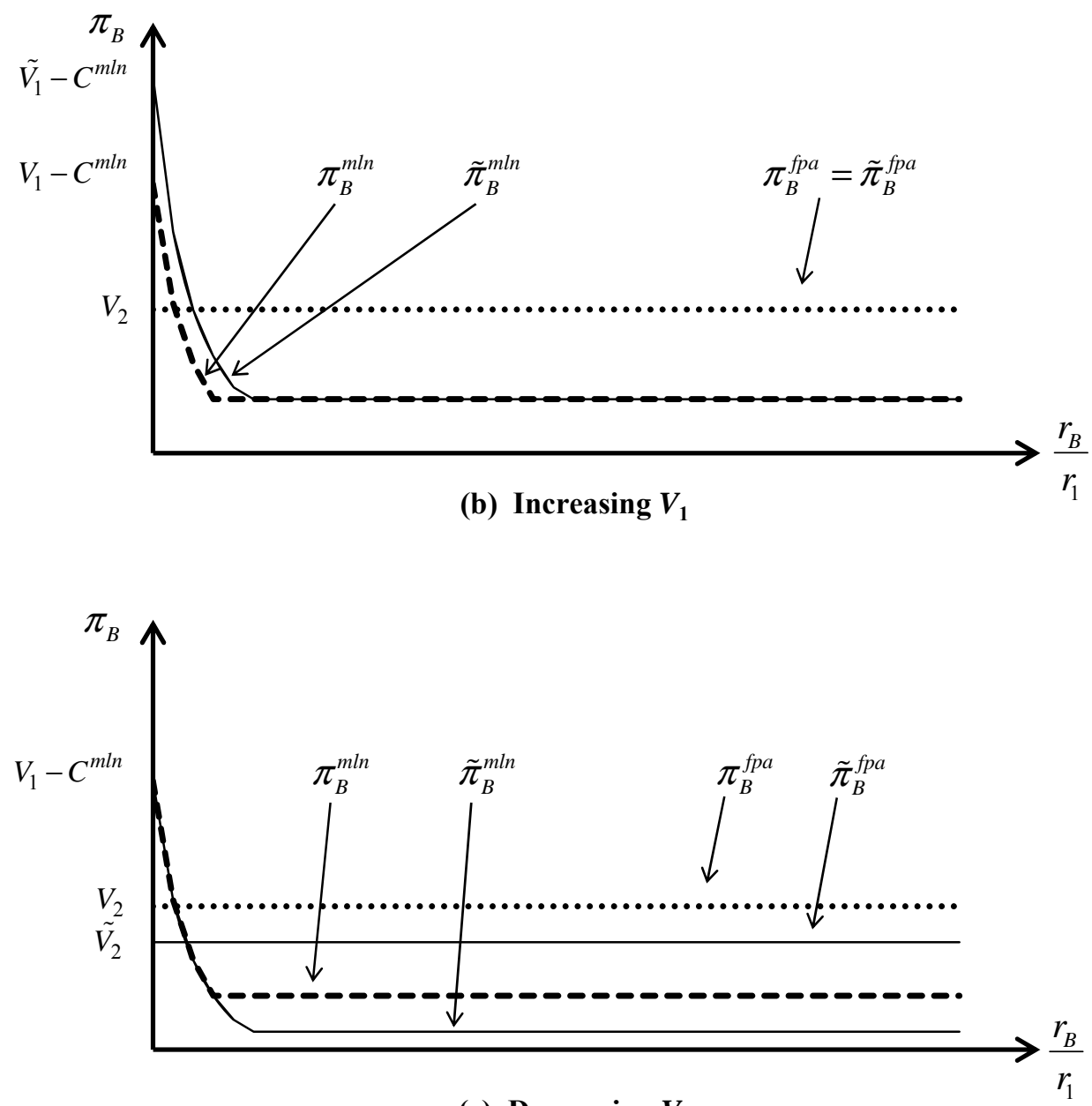

(c) Decreasing $V_{2}$

Figure 3. Comparative Statics of Buyer's Payoffs in Multilateral Negotiations and a First-Price Auction. Each panel shows the buyer's payoffs with initial parameters and with one changed parameter (changes denoted by a tilde). Panel (a) decreases $C^{m l n}$, panel (b) increases $V_{1}$, and panel (c) decreases $V_{2}$. Each change intensifies the buyer's relative preference for multilateral negotiations over a first-price auction. 


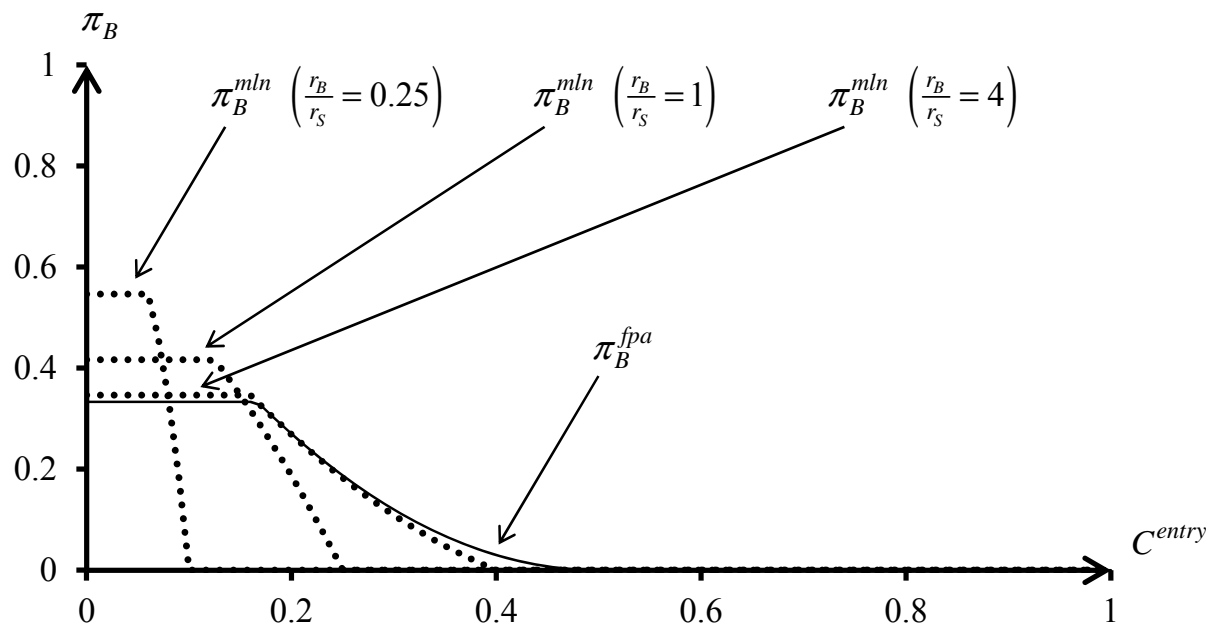

(a) $N=2$

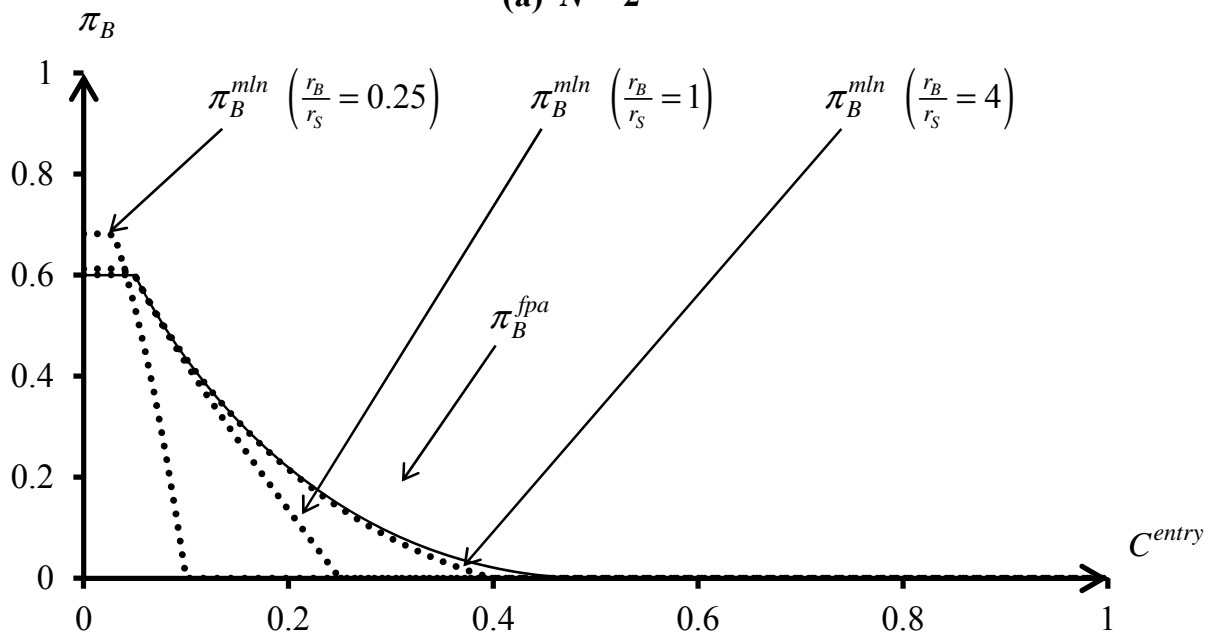

(b) $N=4$

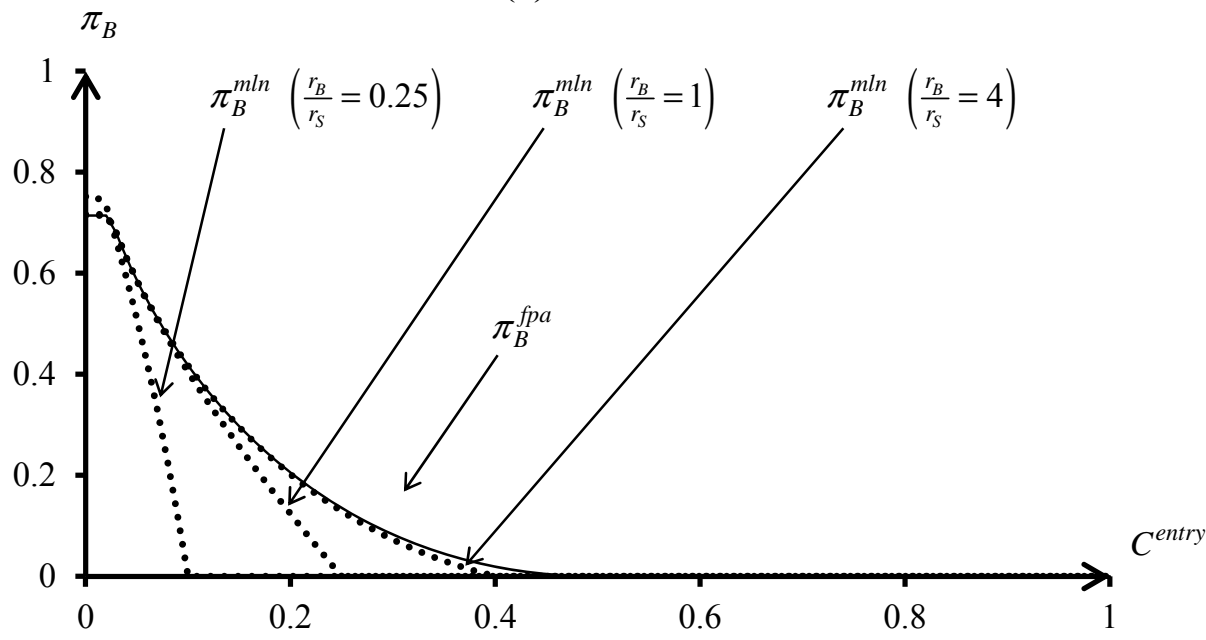

(c) $N=6$

Figure 4. Buyer's Expected Payoffs in Multilateral Negotiations and a First-Price Auction, with Fixed Number of Sellers. Each panel shows the buyer's payoffs for a particular value of $N$, and with different ratios of discount rates $r_{B} / r_{S} . N=2$ in panel (a), $N=4$ in panel (b), and $N=6$ in panel (c). Multilateral negotiation payoffs are dashed lines, first-price auction payoff is solid line. 


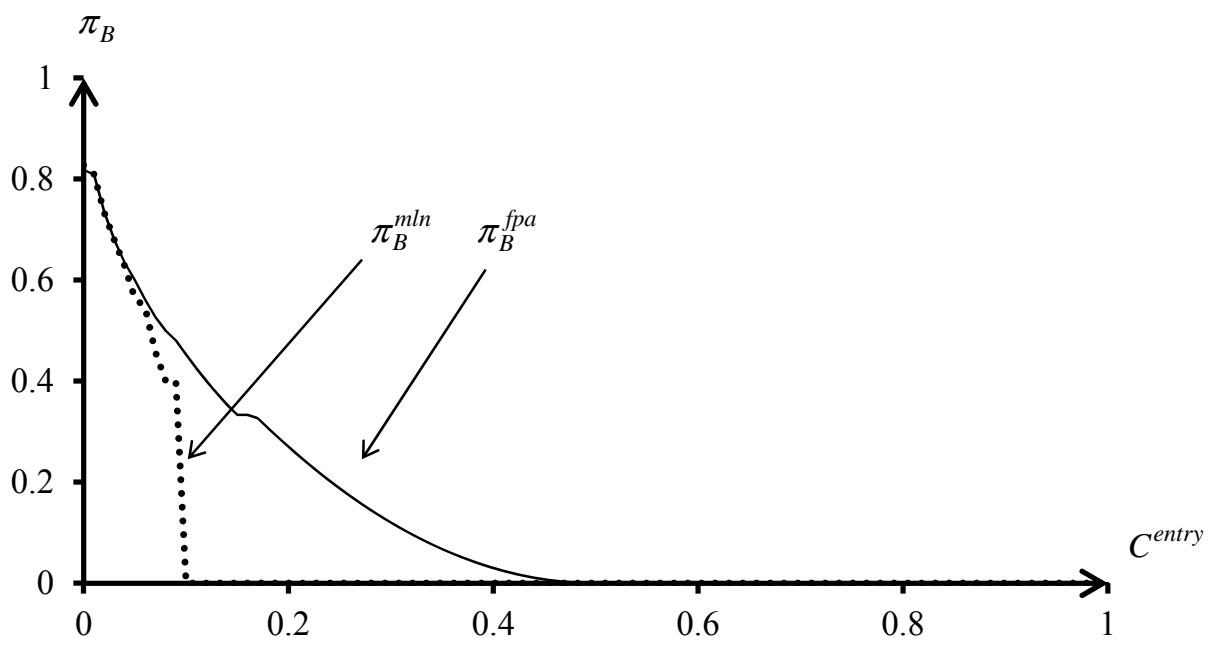
$\pi_{B}$

(a) $r_{B} / r_{S}=0.25$

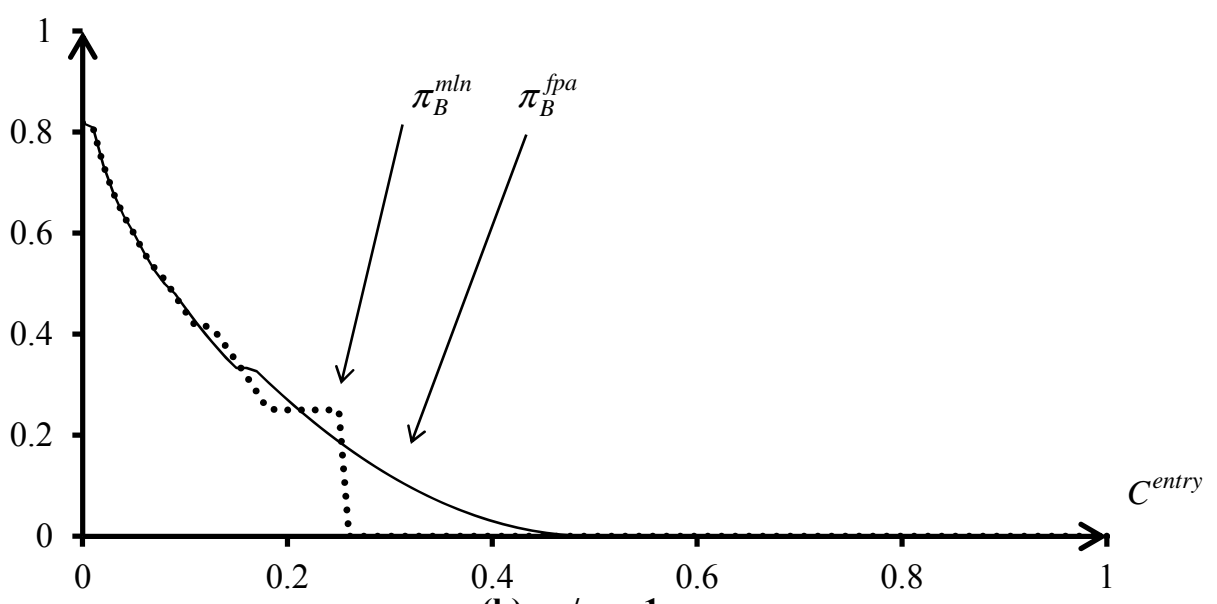

$\pi_{B}$

(b) $r_{B} / r_{S}=1$

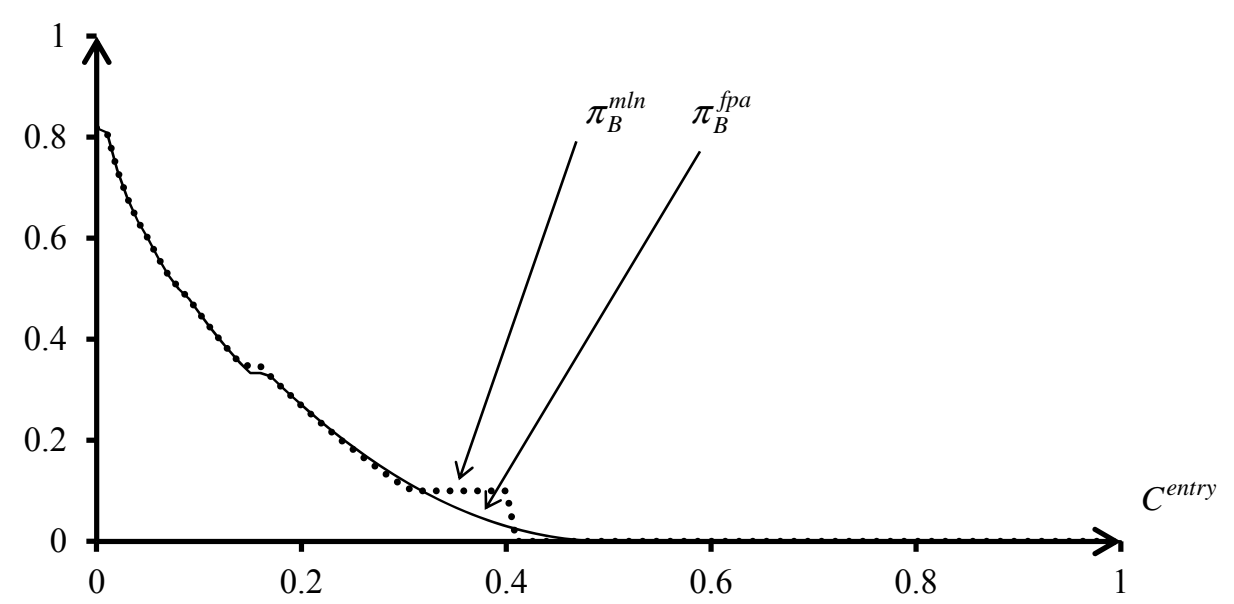

(c) $r_{B} / r_{S}=4$

Figure 5. Buyer's Expected Payoffs in Multilateral Negotiations and a First-Price Auction, with Optimal Number of Sellers. Each panel shows the buyer's payoffs for a particular ratio of discount factors, and with optimal number of invited sellers. $r_{B} / r_{S}=0.25$ in panel (a), $r_{B} / r_{S}=1$ in panel (b), and $r_{B} / r_{S}=4$ in panel (c). Multilateral negotiation payoff is dashed line, first-price auction payoff is solid line. 


\section{2}

\section{Economic Science Institute Working Papers}

12-30 Mago, S., Sheremeta, R. and Yates, A. Best-of-Three Contest Experiments: Strategic versus psychological momentum.

12-29 Bigoni, M., Camera, G. and Casari, M. Strategies of Cooperation and Punishment among Students and Clerical Workers.

12-28 Camera, G. and Kim, J. Buyer's Equilibrium with Capacity Constraints and Restricted Mobility: A recursive approach.

12-27 Camera, G., Casari, M., and Bigoni, M. Binding Promises and Cooperation Among Strangers.

12-26 Schniter, E., Shields, T. and Dickhaut, J. Ageism \& Cooperation.

12-25 Gjerstad, S. and Smith, V. Balance Sheet Crises: Causes, Consequences and Responses.

12-24 Gómez-Miñambres, J., Corgnet, B. and Hernán-Gonzalez, R. Goal Setting and Monetary Incentives: When Large Stakes Are Not Enough.

12-23 Clots-Figueras, I., Hernán González, R., and Kujal, P. Asymmetry and Deception in the Investment Game.

12-22 Dechenaux, E., Kovenock, D. and Sheremeta, R. A Survey of Experimental Research on Contests, All-Pay Auctions and Tournaments.

12-21 Rubin, J. and Sheremeta, R. Principal-Agent Settings with Random Shocks.

12-20 Gómez-Miñambres, J. and Schniter, E. Menu-Dependent Emotions and Self-Control.

12-19 Schniter, E., Sheremeta, R., and Sznycer, D. Building and Rebuilding Trust with Promises and Apologies.

12-18 Shields, T. and Xin, B. Higher-order Beliefs in Simple Trading Models.

12-17 Pfeiffer, G. and Shields, T. Performance-Based Compensation and Firm Value: Experimental evidence.

12-16 Kimbrough, E. and Sheremeta, R. Why Can't We Be Friends? Entitlements, bargaining, and conflict.

12-15 Mago, S., Savikhin, A., and Sheremeta, R. Facing Your Opponents: Social identification and information feedback in contests. 
12-14 McCarter, M., Kopelman, S., Turk, T. and Ybarra, C. Too Many Cooks Spoil the Broth: How the tragedy of the anticommons emerges in organizations.

12-13 Chowdhury, S., Sheremeta, R. and Turocy, T. Overdissipation and Convergence in Rent-seeking Experiments: Cost structure and prize allocation rules.

12-12 Bodsky, R., Donato, D., James, K. and Porter, D. Experimental Evidence on the Properties of the California’s Cap and Trade Price Containment Reserve.

12-11 Branas-Garza, P., Espin, A. and Exadaktylos, F. Students, Volunteers and Subjects: Experiments on social preferences.

12-10 Klose, B. and Kovenock, D. Extremism Drives Out Moderation.

12-09 Buchanan, J. and Wilson, B. An Experiment on Protecting Intellectual Property.

12-08 Buchanan, J., Gjerstad, S. and Porter, D. Information Effects in Multi-Unit Dutch Auctions.

12-07 Price, C. and Sheremeta, R. Endowment Origin, Demographic Effects and Individual Preferences in Contests.

12-06 Magoa, S. and Sheremeta, R. Multi-Battle Contests: An experimental study.

12-05 Sheremeta, R. and Shields, T. Do Liars Believe? Beliefs and Other-Regarding Preferences in Sender-Receiver Games.

12-04 Sheremeta, R., Masters, W. and Cason. T. Winner-Take-All and Proportional-Prize Contests: Theory and experimental results.

12-03 Buchanan, J., Gjerstad, S. and Smith, V. There’s No Place Like Home.

12-02 Corgnet, B. and Rodriguez-Lara, I. Are you a Good Employee or Simply a Good Guy? Influence Costs and Contract Design.

12-01 Kimbrough, E. and Sheremeta, R. Side-Payments and the Costs of Conflict.

2011

11-20 Cason, T., Savikhin, A. and Sheremeta, R. Behavioral Spillovers in Coordination Games.

11-19 Munro, D. and Rassenti, S. Combinatorial Clock Auctions: Price direction and performance.

11-18 Schniter, E., Sheremeta, R., and Sznycer, D. Restoring Damaged Trust with Promises, Atonement and Apology.

11-17 Brañas-Garza, P., and Proestakis, A. Self-discrimination: A field experiment on obesity. 
11-16 Brañas-Garza, P., Bucheli, M., Paz Espinosa, M., and García-Muñoz, T. Moral Cleansing and Moral Licenses: Experimental evidence.

11-15 Caginalp, G., Porter, D., and Hao, L. Asset Market Reactions to News: An experimental study.

11-14 Benito, J., Branas-Garz, P., Penelope Hernandez, P., and Sanchis Llopis, J. Strategic Behavior in Schelling Dynamics: A new result and experimental evidence.

11-13 Chui, M., Porter, D., Rassenti, S. and Smith, V. The Effect of Bidding Information in Ascending Auctions.

11-12 Schniter, E., Sheremeta, R. and Shields, T. Conflicted Minds: Recalibrational emotions following trust-based interaction.

11-11 Pedro Rey-Biel, P., Sheremeta, R. and Uler, N. (Bad) Luck or (Lack of) Effort?: Comparing social sharing norms between US and Europe.

11-10 Deck, C., Porter, D., and Smith, V. Double Bubbles in Assets Markets with Multiple Generations.

11-09 Kimbrough, E., Sheremeta, R., and Shields, T. Resolving Conflicts by a Random Device.

11-08 Brañas-Garza, P., García-Muñoz, T., and Hernan, R. Cognitive effort in the Beauty Contest Game.

11-07 Grether, D., Porter, D., and Shum, M. Intimidation or Impatience? Jump Bidding in On-line Ascending Automobile Auctions.

11-06 Rietz, T., Schniter, E., Sheremeta, R., and Shields, T. Trust, Reciprocity and Rules.

11-05 Corgnet, B., Hernan-Gonzalez, R., and Rassenti, S. Real Effort, Real Leisure and Real-time Supervision: Incentives and peer pressure in virtual organizations.

11-04 Corgnet, B. and Hernán-González R. Don’t Ask Me If You Will Not Listen: The dilemma of participative decision making.

11-03 Rietz, T., Sheremeta, R., Shields, T., and Smith, V. Transparency, Efficiency and the Distribution of Economic Welfare in Pass-Through Investment Trust Games.

11-02 Corgnet, B., Kujal, P. and Porter, D. The Effect of Reliability, Content and Timing of Public Announcements on Asset Trading Behavior.

11-01 Corgnet, B., Kujal, P. and Porter, D. Reaction to Public Information in Markets: How much does ambiguity matter?

\section{0}

10-23 Sheremeta, R. Perfect-Substitutes, Best-Shot, and Weakest-Link Contests between Groups.

10-22 Mago, S., Sheremeta, R., and Yates, A. Best-of-Three Contests: Experimental evidence. 
10-21 Kimbrough, E. and Sheremeta, R. Make Him an Offer He Can't Refuse: Avoiding conflicts through side payments.

10-20 Savikhim, A. and Sheremeta, R. Visibility of Contributions and Cost of Inflation: An experiment on public goods.

10-19 Sheremeta, R. and Shields, T. Do Investors Trust or Simply Gamble?

10-18 Deck, C. and Sheremeta, R. Fight or Flight? Defending Against Sequential Attacks in the Game of Siege.

10-17 Deck, C., Lin, S. and Porter, D. Affecting Policy by Manipulating Prediction Markets: Experimental evidence.

10-16 Deck, C. and Kimbrough, E. Can Markets Save Lives? An Experimental Investigation of a Market for Organ Donations.

10-15 Deck, C., Lee, J. and Reyes, J. Personality and the Consistency of Risk Taking Behavior: Experimental evidence.

10-14 Deck, C. and Nikiforakis, N. Perfect and Imperfect Real-Time Monitoring in a Minimum-Effort Game.

10-13 Deck, C. and Gu, J. Price Increasing Competition? Experimental Evidence.

10-12 Kovenock, D., Roberson, B., and Sheremeta, R. The Attack and Defense of Weakest-Link Networks.

10-11 Wilson, B., Jaworski, T., Schurter, K. and Smyth, A. An Experimental Economic History of Whalers' Rules of Capture.

10-10 DeScioli, P. and Wilson, B. Mine and Thine: The territorial foundations of human property.

10-09 Cason, T., Masters, W. and Sheremeta, R. Entry into Winner-Take-All and Proportional-Prize Contests: An experimental study.

10-08 Savikhin, A. and Sheremeta, R. Simultaneous Decision-Making in Competitive and Cooperative Environments.

10-07 Chowdhury, S. and Sheremeta, R. A generalized Tullock contest.

10-06 Chowdhury, S. and Sheremeta, R. The Equivalence of Contests.

10-05 Shields, T. Do Analysts Tell the Truth? Do Shareholders Listen? An Experimental Study of Analysts' Forecasts and Shareholder Reaction.

10-04 Lin, S. and Rassenti, S. Are Under- and Over-reaction the Same Matter? A Price Inertia based Account. 
10-03 Lin, S. Gradual Information Diffusion and Asset Price Momentum.

10-02 Gjerstad, S. and Smith, V. Household Expenditure Cycles and Economic Cycles, 1920 - 2010.

10-01 Dickhaut, J., Lin, S., Porter, D. and Smith, V. Durability, Re-trading and Market Performance.

2009

09-11 Hazlett, T., Porter, D., and Smith, V. Radio Spectrum and the Disruptive Clarity OF Ronald Coase.

09-10 Sheremeta, R. Expenditures and Information Disclosure in Two-Stage Political Contests.

09-09 Sheremeta, R. and Zhang, J. Can Groups Solve the Problem of Over-Bidding in Contests?

09-08 Sheremeta, R. and Zhang, J. Multi-Level Trust Game with "Insider" Communication.

09-07 Price, C. and Sheremeta, R. Endowment Effects in Contests.

09-06 Cason, T., Savikhin, A. and Sheremeta, R. Cooperation Spillovers in Coordination Games.

09-05 Sheremeta, R. Contest Design: An experimental investigation.

09-04 Sheremeta, R. Experimental Comparison of Multi-Stage and One-Stage Contests.

09-03 Smith, A., Skarbek, D., and Wilson, B. Anarchy, Groups, and Conflict: An experiment on the emergence of protective associations.

09-02 Jaworski, T. and Wilson, B. Go West Young Man: Self-selection and endogenous property rights.

09-01 Gjerstad, S. Housing Market Price Tier Movements in an Expansion and Collapse.

2008

08-09 Dickhaut, J., Houser, D., Aimone, J., Tila, D. and Johnson, C. High Stakes Behavior with Low Payoffs: Inducing preferences with Holt-Laury gambles.

08-08 Stecher, J., Shields, T. and Dickhaut, J. Generating Ambiguity in the Laboratory.

08-07 Stecher, J., Lunawat, R., Pronin, K. and Dickhaut, J. Decision Making and Trade without Probabilities.

08-06 Dickhaut, J., Lungu, O., Smith, V., Xin, B. and Rustichini, A. A Neuronal Mechanism of Choice.

08-05 Anctil, R., Dickhaut, J., Johnson, K., and Kanodia, C. Does Information Transparency

Decrease Coordination Failure? 
08-04 Tila, D. and Porter, D. Group Prediction in Information Markets With and Without Trading Information and Price Manipulation Incentives.

08-03 Thomas, C. and Wilson, B. Horizontal Product Differentiation in Auctions and Multilateral Negotiations.

08-02 Oprea, R., Wilson, B. and Zillante, A. War of Attrition: Evidence from a laboratory experiment on market exit.

08-01 Oprea, R., Porter, D., Hibbert, C., Hanson, R. and Tila, D. Can Manipulators Mislead Prediction Market Observers? 